\title{
Pore-Facies as a tool for incorporation of small scale dynamic information in integrated reservoir studies
}

\author{
A. Chehrazi ${ }^{1}$, R. Rezaee ${ }^{2}$, H. Rahimpour ${ }^{1}$ \\ 1. School of Geology, University College of Science, University of Tehran, Tehran, Iran \\ 2. Department of Petroleum Engineering, Curtin University of Technology, Perth, Australia
}

\begin{abstract}
In this study, the quantification and incorporation of pore geometry, a qualitative parameter, and as a source of dynamic information, will be demonstrated in the integrated reservoir studies. To quantify pore geometry, Mercury Injection Capillary Pressure (MICP) curves have been exploited. For each MICP curve, 20 parameters were derived and Multi Resolution Graph based Clustering (MRGC) was applied to classify the curves into 9 representative distinct clusters. The number of clusters was determined based on petrography and cluster analysis. The quantified pore geometry in terms of discrete variable, have been called Pore-Facies, and like Electro-Facies and Litho-Facies could be used in facies modeling and rock typing phases of integrated study. Dependency of dynamic reservoir rock properties into pore geometry makes the Pore-Facies as an interesting and powerful approach for incorporation of small scale dynamic data into reservoir model.

A comparison among various facies definitions proved that neither Litho-Facies, nor Electro-Facies is capable to characterize dynamic rock properties and the best results were achieved by Pore-Facies method. Based on this study, it is recommended that for facies analysis in reservoir modeling, methods based on pore characteristics such as Pore-Facies, introduced in this article, be used rather than traditional facies that rely on matrix properties. The next generation of the reservoir models which incorporate Pore-Facies based rock types, will provide a basis for more accurate static and dynamic models, a narrower range of uncertainty in the models, and a better prediction of reservoir performance.
\end{abstract}

Keywords: pore geometry, Pore-Facies, reservoir modeling, facies analysis, rock typing, MICP curves,

\section{Introduction}

Geological modeling of a reservoir represents one of the most important phases in the workflow of a typical reservoir study, concerning the volume of work involved and the impact on the final results. The relevance of a sound geological model in the overall reliability of a reservoir study has been repeatedly emphasized in the technical literature (Graaff and Ealey, 1989, Martin et al., 1999, Seifert et al., 1999, Doligez et al., 1999), being long recognized that the static description of the reservoir, both in terms of geometry and petrophysical properties, is one of the main concerning factors in determining the field production performance (e.g., Cosentino, 2001). 
Geological model includes static properties such as geometrical properties i.e. structural and stratigraphic models and models of rock or petrophysical properties such as facies, porosity, and water saturation. Assigning parameters of rock-fluid interactions and fluid properties to each cell of static model, results in dynamic model. Wettability, capillarity, relative permeability and residual oil saturation are considered as rock fluid interactions.

In most of the operational studies, it is a common tradition to exploit the relationship between static description and field performance as a measure of the accuracy of the geological model. In other words, the geological studies are often performed using static information alone, i.e. seismic, log and core data, while the dynamic information is used only to check the observed reservoir performance. This could be referred to as an a posteriori control. In an integrated geological model, however, the dynamic information should be better used as a direct input, i.e., a priori constraint.

A correct description of petrophysical properties of the reservoir rock and understanding the close relationships existing between porous network, rock properties and fluid flow and incorporating reservoir dynamic properties into static reservoir models in all scales forms the cornerstone of the integrated reservoir study and is therefore a fundamental requisite to correctly represent the dynamic behavior of the field in the numerical simulation study.

For integrated reservoir characterization it is possible to incorporate dynamic reservoir information in all scales and in all stages of static modeling. However there are two problems for integration of dynamic data into static models. First, while reservoir models are quantitative in nature, most of geological variables are inherently qualitative and hence before using such variables in any model, it is necessary to represent them by some quantitative parameters. For example, pore geometry is a micro scale geological variable, and has been treated as a qualitative parameter. The Second issue which must be considered is the phases of static modeling that dynamic data can be incorporated. For example, pore geometry is a parameter which after quantification, can be used among the various stages of static models, in facies analysis and rock type definition.

Discussing all static models and how to incorporate dynamic data in each model is beyond the scope of this article. In this study only the quantification and incorporation of pore geometry as a controlling parameter for most of petrophysical properties, in facies analysis and rock typing, will be discussed. Usually facies analysis in an integrated reservoir study consist of 1- facies definition at cored sections, 2- Prediction of defined facies for un-cored wells, 3- Population of facies for whole reservoir using Geostatistical techniques. The emphasis of this study is definition of facies in cored section. The concepts of pore characteristics i.e. pore type and pore geometry will be introduced and various definitions of these parameters and different techniques for quantifying pore geometry will be discussed briefly. The usefulness of MICP (Mercury Injection Capillary Pressure) curve as an indicator of pore geometry will be illustrated using 231 high pressure MICP curves from Dorood field located in Iranian sector of the Persian Gulf and a method for quantification of a qualitative parameter like pore geometry will be shown using parameterization and classification of MICP curves. For the purpose of MICP curve parameterization, 20 attributes will derived for each curve and MRGC (Multi Resolution Graph based Clustering) will be applied for clustering of curves into 9 representative Pore-Facies. 
Then, the stage at which such a quantified parameter could be used in an integrated reservoir study will be illustrated. Various definitions of conventional facies analysis like Litho-Facies, Electro-Facies and Petro-Facies and also the concept of rock typing will be explained in brief and the basics for Pore-Facies, which in contrast with other facies definitions is based on pore characteristics will be demonstrated.

To compare various techniques of facies analysis in characterization of dynamic reservoir properties and to illustrate advantages of Pore-Facies analysis and direct reservoir rock typing for permeability prediction, clustering of MICP curves based on various facies definitions and also the sensitivity of this facies to permeability variations will be shown. And finally the improved method of MICP curve averaging instead of traditional Leverett J-Function will be discussed.

\section{Geological Setting}

Dorood oil field, the largest Iranian offshore oil field, $25 \mathrm{~km}$ long and $5 \mathrm{~km}$ wide, is located offshore in the northern part of the Persian Gulf area. This field partly underlies the Kharg Island (figure 1). The Dorood structure is an elongated anticline plunging toward north and north-east and is linked to both Zagros and Arab orogenies. Lower Cretaceous Fahliyan Formation is the main proven pay zone of Dorood structure. The major lithology is limestone capped by the micritic limestone of Lower Gadvan Formation which is also identified as the seals of the reservoir. Fahliyan Formation is divided into Manifa member, corresponding to the best reservoir zone; middle Yamama section, corresponding to the major reservoir interval; and upper Yamama section corresponding to poor reservoir quality limestones (figure 2). The whole reservoir interval is made of limestones, with very limited content of dolomite and anhydrite.

\section{Available Data and Laboratory Procedures}

Up to now, more than 90 wells have been drilled in Dorood Field. A complete suite set of well log data from 80 wells were available for this study. Core data set were carefully examined, and a total of 3294 core porositypermeability, 231 Mercury Injection capillary pressure and 400 thin sections from Wells D-101P, D-103WI and D-106P were selected for this study.

For measuring porosity and permeability, total core gamma was first run on the core, one and half inch diameter plug samples were drilled, and samples were cleaned in a soxhlet extraction apparatus using hot toluene and methanol. Samples were then dried in a regular oven at $116^{\circ} \mathrm{C}$. Weight, length and the diameter of each plug sample were measured and grain volume and grain density were then determined using Core Laboratories Ultraporosimeter. Porosity and permeability values were measured at a net overburden pressure of $29500 \mathrm{kPa}$ (4279 psi) using CMS - 300 ${ }^{\mathrm{TM}}$. All reported permeabilities are Klinkenberg permeability.

For MICP curves, each sample, trimmed to approximately 1 by 1 inch. The clean dry core samples were weighed and each placed in the bulb of a penetrometer. The sample and penetrometer were weighed together. 
The penetrometer containing the sample was loaded into the low-pressure chamber of a Micromeritics Autopore II 9220 porosimeter. The penetrometer was evacuated to a pressure of less than $50 \mu \mathrm{m}$ of mercury, and then filled with mercury at a pressure of $3.45 \mathrm{kPa}(0.5 \mathrm{psi})$. The bulk volume of the sample was determined at this point. Mercury was injected into the core plug at increasing incremental pressures from $3.45 \mathrm{kPa}$ (0.5 psi) to 172 $\mathrm{kPa}(25 \mathrm{psi})$. The injection pressure was reduced to atmospheric and the penetrometer was removed and weighed with the sample and mercury in place. It was then loaded into a high-pressure chamber of the Autopore system. The cumulative volume of mercury injected is increased by incremental pressure changes up to a maximum of approximately $413685 \mathrm{kPa}(60,000 \mathrm{psi})$ with data being recorded at each pressure. Monitoring the change in pressure over a specific period of time, (120 seconds), identifies equilibrium. If the pressure remains above $99.5 \%$ of the set injection pressure over this period then equilibrium is assumed otherwise pressure is reset, and monitored again over the equilibration time. This is repeated until equilibration is achieved at each pressure. Sample weight, sample and penetrometer weights with and without mercury were used to calculate grain density and bulk density. Volumes of mercury injected at each injection pressure were recorded. Cumulative volumes of mercury injected at each stable pressure are expressed as a fraction of the total pore volume of the sample.

\section{Pore Characteristics; pore type and pore geometry as a source of dynamic data}

Geologists and petroleum engineers have always been interested in the study of the rocks' pore characteristics as they regulate the storage capacity and deliverability of hydrocarbon reservoirs (Wardlaw and Taylor, 1976; Bos, 1982). Pore characteristics are classified as pore type and pore geometry, each of which has completely different nature and definition. They are the controlling parameters for most of petrophysical properties of reservoir rocks (Leverett, 1941; Archie, 1942, \& 1952; Biot, 1953, Morgan and Gordon, 1970; Jackson et al., 1978; Wilkens et al. 1984; Tao \& King, 1993; Xu and White, 1995\&1996; Tiab et. al., 2004). Therefore, understanding complex variation in pore geometry and pore type is the key to improve reservoir description and exploitation. Analysis of pore geometry allows reservoir characterization to be pore system oriented and the resulting reservoir models are based on characteristics of pore system.

Pore type is the term for classifying porous part of the rock into groups of (always) genetically related pore spaces characterized by similar depositional and diagenetic history. Each pore type is identified based on its origin and geological processes which were active during the sedimentation and lithification of the rock. Several attempts have been made at integrating engineering and geological information and for the purpose of classification of pore types (Archie, 1952, Choquette \& Pray 1970, Lucia, 1983; 1995b; 1999 and Lønøy, 2006).

Pore geometry is the other pore characteristic that has more direct relation with petrophysical properties. The fundamental relationships between pore geometry and basic rock properties (e.g., effective porosity, absolute permeability, etc.) are well-documented in the petroleum and petrophysics literature (Morgan and Gordon ,1970, Wardlaw and Taylor, 1976; Bos, 1982, Xu and White 1995, 1996, Tiab et. al., 2004). One important advantage of pore geometry over pore type is that, it can be better represented by quantitative 
attributes. Pore geometry refers to the architecture and internal anatomy of the rock. It is defined by textural properties of pores such as size, size distribution, shape, throat size, throat size distribution, aspect ratio, coordination number, pore arrangement and tortuosity. These parameters are combined to yield a classification of the various pores in the rocks. The term "pore geometry" as can be implied, is not a complete representative term for all of these attributes. In addition no individual technique is able to capture all of these attributes; instead each technique can handle some of them. In the following section, various techniques for characterization of pore geometry are discussed.

\section{Acquiring some measure of pore geometry}

Petrography, image analysis, mercury injection capillary pressure (MICP), and nuclear magnetic resonance (NMR) provide pore-geometry parameters useful for understanding variations in rock properties (Basan et al., 1997). A few researchers used petrographic image analysis (PIA) to establish the relationship between pore geometry and rock properties. These studies attempted to overcome the limitations inherent in visualization techniques by classifying pore types based on measurement parameters (Ehrlich et al. 1984, 1991). MICP pore size is an area-equivalent diameter of the throats connecting the pore system. The MICP distribution contains a point (the turning point) that reveals where mercury first encounters the permeable network. This point identifies both critical pore size and connected porosity. Brownstein \& Tarr (1979) showed that NMR relaxation rate is proportional to the surface area-to-volume ratio of pores in tissue. The early works of Brown \& Gamson (1960), Seevers (1966) and Timur (1969) revealed the potential of NMR application in obtaining rock properties such as pore size distribution. NMR pore size is a derivative of the pore-surface volume ratio. Like MICP, NMR provides a pore-size distribution that represents the entire sample volume. Used individually, each laboratory measurement has a place in reservoir evaluation because each portrays the pore system in a slightly different way. MICP, PIA and NMR measurements differ, especially in the way they characterize the volume of the system (Basan et al., 1997).

\section{Mercury injection capillary pressure (MICP)}

Capillary pressure is the pressure difference existing across the interface separating two immiscible fluids. It critically affects initial reservoir fluid distribution and petroleum recovery during primary or enhanced production. The distribution of multiple fluids in reservoir pores is a function of capillary forces, which in turn are related to system wettability, fluid density and pore geometry. Capillary pressures data have, in the past, been used primarily to evaluate reservoir rock quality, calculate oil columns or estimate relative permeability characteristics. Today, capillary pressure measurements have widespread applications including calculation of original oil in place, detailed characterization of heterogeneous reservoirs, prediction of primary production, evaluation of enhanced recovery methods, evaluation of seal capacity, defining transition zone fluid distribution, 
calculation of average water saturation, determination of connate water saturation and to determine initial water saturation.

One of the most important and frequently cited applications for MICP curve is to derive absolute permeability from some attributes extracted from MICP curves which highlight the interdependency of these parameters (Purcell, 1949, Calhoun, et al., 1949, Burdine et al., 1950, Wyllie \& Spangler, 1952, Thomeer, 1960, Swanson, 1981, Wells \& Amaefule, 1985). In addition to dependency of capillary pressure on reservoir properties, numerous researchers emphasized that the shape of the capillary pressure curve may be primarily affected by pore geometry (e.g. Rose \& Bruce, 1949).

It appears that MICP curves, that reflect capillary pressure of a reservoir rock, are suitable representatives for quantification of pore geometry and incorporation of dynamic data into reservoir models.

\section{Quantifying the pore geometry using MICP curves}

As it is evident from previous discussion, pore geometry is one of the most important sources of dynamic data for integration into static models. MICP curves can be used to extract pore geometrical properties which are important for both static and dynamic reservoir properties. For integration of pore geometrical parameters, however, the first step is to obtain some quantitative data from MICP curves. Although MICP curve is made up of connection of mercury saturation-pressure points which are numerical variables and hence quantitative by itself, but since the final goal is pore geometry and not the MICP curve itself, it is required to extract some parameters that are related to pore geometry. This stage of the work is called MICP curve parameterization.

In addition to be usable in facies analysis of static model, it should be represented by a discrete variable. This step of the work is called classification. So, what we mean with quantification of MICP curves is, to parameterize and to classify these curves in such a way that each curve could be represented by a class label or category of discrete variables. This categorical variable, we call it facies, can be used directly for facies analysis and rock typing part of integrated reservoir study.

\subsection{MICP curve parameterization}

There is not a simple correlation between pore geometry and capillary pressure curve properties. Because, pore geometry by definition is not a simple metric, instead it is a complex parameter characterized by quantitative and qualitative properties. In addition, capillary pressure curve itself could not be represented by a single parameter. In fact the variety of capillary models and numerous parameters extracted from capillary pressure curve, which are related to some features of pore geometry by theoretical or empirical equations, arises from such a complex relationship. To solve this problem, it is possible to derive various parameters of capillary pressure curve and classify the curves accordingly. 
As illustrated in figure 3, classifying capillary pressure curves by visual inspection alone is nearly impossible, because these curves span the whole range of the water saturation against the capillary pressure plot (figure 3). However, it is possible to extract some parameters from MICP curves (parameterization) and classify them into a number of discrete groups using clustering techniques (classification).

In this study, we extracted two data sets from MICP curves. The first set includes the pressure equivalent of different water saturations. Numerous Capillary Models have been developed for this purpose to simulate the capillary pressure responses of rocks (Corey, 1954, Thomeer, 1960, Brooks \& Corey, 1966, Van Genuchten, 1980, Lenormand, 1990, Donaldson et al, 1991, Skelt and Harrison, 1995, Jing and Wunnik, 1998, Li and Horne, 2002, Huet et al., 2005). No single method could handle all capillary pressure curves for whole range of water saturations, but it seems that a combination of Leverett $\mathrm{J}$ function and pore geometrical factor is a better representative than any single capillary model. In this study equivalent capillary pressure for $5,16,25,35,50,75$, 84 and 95 percent saturations and also entry and threshold pressures, were extracted from MICP curves. The numbers are not arbitrary in that, 16, 50 and 84 and sometimes 25,35 and 75 percent saturations make the plateau part of the curve and are used for pore throat sorting calculations. The 5 and 95 percent saturations were selected so that the lower and upper range of capillary pressure or pore throat sizes to be taken into account.

It must be noted that it is not only the shape of the curves which is important but the relative position of the curves when is plotted on PC vs. saturation that depends on pore geometry must be also considered. The second data set extracted from MICP curves comprises the parameters which are related to pore characteristics via some theoretical or empirical relations. After cross-plotting these parameters versus permeability, attributes with highest correlation were selected for cluster analysis. These parameters are explained in the following section and are displayed in figure 4.

Entry Pressure, Pe: It can be estimated from the initial shape of early injection into the sample and can be defined as the pressure at which the mercury first starts to be intrude into the sample.

Threshold Pressure: The threshold pressure, where mercury begins to inject into the pore structure, is identified at the pressure where the rate of mercury injection increases rapidly. The threshold pressure, as defined graphically by Thompson et al., (1987), corresponds to the inflection point at which the curve becomes convex upward. Cumulative apparent injection up to this threshold pressure is subtracted as surface porosity from measured data before subsequent calculations are made.

Pore Throat Radius: At any mercury displacement pressure the minimum radius of pore throat can be penetrated by mercury is given by Laplace's equation:

$$
r=\frac{2 \sigma \cdot \cos \theta \cdot C}{P C}
$$

where $r$ is pore throat radius in $\mu \mathrm{m}, \sigma$ is interfacial tension between air and mercury $\mathrm{kPa}(0.0485$ equal to 485 dynes/cm), $\theta$ is contact angle between air and mercury in degrees (140), Pc is capillary pressure in $\mathrm{kPa}$ and $\mathrm{C}$ is conversion constant. 
Oil-Brine Capillary Pressure: Oil-Brine capillary pressure in reservoir condition is obtained from airmercury data by the following conversion:

$$
P C_{o b}=P C_{a H g} \cdot \frac{\sigma_{2} \cdot \cos \theta_{2}}{\sigma_{1} \cdot \cos \theta_{1}}
$$

where $\mathrm{Pc}_{\mathrm{ob}}$ is oil-brine capillary pressure (reservoir) in $\mathrm{kPa}, \mathrm{Pc}_{\mathrm{aHg}}$ is air-mercury capillary pressure in $\mathrm{kPa}$, $\sigma_{2}$ is interfacial tension between oil and brine (reservoir) in $\mathrm{kPa}(0.003), \theta_{2}$ is contact angle between oil and brine (reservoir) in degrees (30), $\sigma_{1}$ is interfacial tension between air and mercury in $\mathrm{kPa}(0.0485)$ and $\theta_{1}$ is contact angle between air and mercury in degrees (140).

Mean Hydraulic Radius (MHR): MHR is the average pore throat size of the sample and is given by the following equation. This parameter is an Integral of pore throat radius ( $r$ ) for all values of water saturations:

$$
M H R=\frac{\sum_{i=0}^{n}\left(r_{i}^{2} \cdot\left(S_{i}-S_{i-1}\right)\right)}{2 \cdot \sum_{i=0}^{n}\left(r_{i} \cdot\left(S_{i}-S_{i-1}\right)\right)}
$$

where $r_{i}$ is the pore throat radius (micron) and $S_{i}$ is mercury saturation (fraction of pore volume) at $i$ saturation.

Height Above Free Water Level (HAFWL) and Fluid Contacts: Within the reservoirs, the fluids are distributed as a function of two forces: capillary pressure and buoyancy. At free water level where the pores are saturated with water, capillary pressure is zero and as the distance increases from this level capillary pressure is also increases. So we can use the capillary pressure data based on this relationship for obtaining an idea of height above free water level. Using this parameter vs. water saturation it is possible to have water saturation in each depth level which is important for distribution of water saturation throughout the field. HAFWL can be calculated as follows:

$$
H=\frac{0.102 P c_{(r e s)}}{\left(\rho_{w}-\rho_{o}\right)}
$$

where $\mathrm{H}$ is height above free water level in meter, $\mathrm{Pc}_{(\mathrm{res})}$ is equivalent oil/brine reservoir capillary pressure in $\mathrm{kPa}, \rho_{\mathrm{w}}$ is water density at reservoir conditions $\left(1.15 \mathrm{~g} / \mathrm{cm}^{3}\right)$ and $\rho_{\mathrm{o}}$ is oil density at reservoir conditions $(0.67$ $\left.\mathrm{g} / \mathrm{cm}^{3}\right)$.

Oil columns can be calculated for any oil saturation, but, for comparison purposes, are fixed at $50 \%$ and $75 \%$. The numbers are not arbitrary in that a $50 \%$ oil saturation will commonly yield a marginal to fair well, while oil saturation of $75 \%$ or greater can be expected to yield good to excellent wells. The oil column required for $50 \%$ oil saturation provides an estimate of minimum vertical trap closure. 
Pore Throat Size Distribution, PTSD: a graph of fraction of pore volume injected (v) versus pore throat radius can be constructed. Pore throat radius has been derived using Laplace's equation. The differential of this gives a pore throat size distribution (PTSD) function. This function gives a numeric value for each pore throat size, which varies from 0 to 1 . 1 will be assigned to most popular pore throat size and pore throat sizes which haven't any value will be zero.

$$
P T S D=\frac{d v}{d \log (r)}
$$

PTSD is smoothed using 1-2-1 smoothing:

$$
P T S D_{i}=\left(P T S D_{i-1}+2 P T S D_{i}+P T S D_{i+1}\right) / 4
$$

PTSD is then normalised to 1 as follows:

$$
P T S D_{\text {normal ized }}=P T S D_{i} / P T S D_{\text {Max }}
$$

The normalised pore throat size distribution function can be used to identify pore throat size groupings and the relative proportions of pore volume controlled by macro pore throats $(>1.5 \mu \mathrm{m})$, meso pore throats $(1.5$ to $0.5 \mu \mathrm{m})$ and micro pore throats $(<0.5 \mu \mathrm{m})$, labelled as macro-ports, meso-ports and micro-ports, respectively (figure 4).

Reservoir Grade, RG: RG indicates the reservoir quality of rock and is the area integrated under the MICP curve when the saturation and pressure are plotted linearly. While PTSD measures the range in pore throat size, RG gives a relative number to the size of the pore throats. A low RG number indicates large pore throats and ability to accept oil saturation at low capillary pressures. The larger the RG number, the smaller the pore throats and greater the capillary pressure needed to obtain economic oil saturations. RG shows better correlation with porosity than permeability.

Pore Throat Sorting, PTS: as the name implies is a number that measures the sorting of the pore throats within the rock sample. In fact PTS provides a measure of pore geometry by applying a numerical value to the slope of the plateau found on a semi-log plot of capillary pressure data. There are several equations for calculation of PTS. One of these equations uses the sorting coefficient equation:

$$
\text { PTS }=\left[\frac{3 r d \text { Quartile Pr essure }}{1 \text { st Quartile Pressure }}\right]^{1 / 2}
$$

where the first and third quartile pressures are directly obtained from the MICP curve and reflect the 25 and $75 \%$ mercury saturation pressure adjusted for irreducible water saturation. A PTS value of 1.0 represents a perfect horizontal plateau while values much above 5.0 pertain to curves displaying little or no plateau development. Another equation which sometimes better represents the plateau part of MICP curve and in this study was applied, uses mean values of 16,50 and $84 \%$ mercury saturation pressure as follows: 


$$
P T S=\frac{P_{16}+P_{50}+P_{84}}{3}
$$

The significance of PTS centres on the rock's ability to accept oil saturation. In well sorted rocks, once the threshold buoyancy pressure is obtained, oil will rapidly saturate the available porosity up to the maximum capacity. Poorly sorted pores require a pressure increase over a much broader range to obtain the same level of oil saturation.

Pore Geometrical factor: In 1960, Thomeer observed that a log-log plot of capillary pressure could be approximated by a hyperbola. Thomeer described the hyperbola location on the $\mathrm{x}-\mathrm{y}$ coordinate system by the position of the two end-point curve asymptotes, and he defined the extrapolated asymptotes on the $\mathrm{x}$ - and $\mathrm{y}$-axes as the displacement pressure and the bulk volume occupied by mercury at an infinite pressure, respectively. Thomeer hypothesized that the shape of the hyperbola reflects the pore geometry, so he used the curve shape to define a pore geometrical factor. Thomeer assigned the pore geometric factor a value between 0 and 10 , where low values represent large well-sorted pore openings and high values represent high levels of variation in pore opening sizes. The Thomeer model can be given as:

$$
\frac{S_{b}}{S_{b_{\infty}}}=e^{-G /\left[\log \left(p_{c} / p_{d}\right)\right]}
$$

where $\mathrm{pc}$ is capillary pressure $(\mathrm{kPa}), \mathrm{p}_{\mathrm{d}}$ is capillary displacement pressure $(\mathrm{kPa}), \mathrm{S}_{\mathrm{b}}$ is $\mathrm{Hg}$ saturation (fraction), $\mathrm{S}_{\mathrm{b} \infty}$ is $\mathrm{Hg}$ saturation at $\mathrm{pc}=\infty$ (fraction) and $\mathrm{G}$ is pore geometrical factor (dimensionless).

Pore Size Distribution (PSD): PSD reflects the pore size distribution in the same manner as does pore throat sorting. A method developed by Brooks and Corey (1964), can be used to estimate PSD. The technique involves determining the slope of the best fit line through a log-log plot of J-function versus $\mathrm{S}_{\mathrm{w}}$. PSD is then calculated as $-1 /$ slope of the line. It is also possible to cross-plot J-function (on the $\mathrm{Y}$ axes) and $\mathrm{S}_{\mathrm{w}}$ (on the $\mathrm{X}$ axes) in linear scale, but instead of linear function, a power law equation is used. Here the exponent of independent variable $\left(\mathrm{S}_{\mathrm{w}}\right)$ will show the PSD.

Swanson's parameter: The technique involves determining Swanson's parameter $(\mathrm{Sb} / \mathrm{Pc})_{\mathrm{A}}(\mathrm{where} \mathrm{Sb}=$ mercury saturation, \% bulk volume) which is related to the effective pore space contributing to fluid flow and the corresponding injection pressure (Swanson, 1981). The Swanson parameter is determined by calculating $(\mathrm{Sb} / \mathrm{Pc})$ at all pressures for any sample and taking the maximum of these values. It is recommended that a crossplot of actual measured permeabilities against the Swanson parameter be used to better define the correlation coefficients for the formation in question.

Cross-plots of various parameters extracted from MICP curves versus permeability along with their $\mathrm{R}^{2}$ are displayed in figure 5. Since in many of studies, relationship between porosity and permeability has been used as a tool for estimation of permeability in un-cored wells; as it is believed that porosity is a parameter which controls the permeability, cross-plot of porosity and permeability is also displayed in this figure. An interesting 
observation here is that, while the $\mathrm{R}^{2}$ between porosity and permeability is less than 0.6 , most parameters extracted from MICP curves, show $\mathrm{R}^{2}$ greater than 0.8 , much larger than that of porosity which is a significant improvement and highlights this point that these parameters have more control on permeability. One more interesting observation is that, equivalent pressure of $35 \%$ mercury saturation has the largest $\mathrm{R}^{2}$ with permeability, something that first was documented by Winland.

\subsection{Clustering and classification of MICP curves}

Clustering is a process of partitioning a set of data (or objects) in a set of meaningful sub-classes, called clusters such that objects belonging to the same cluster are similar, while those belonging to different ones are dissimilar. Clustering is an unsupervised classification where the class labels and the number of classes are unknown. In this study a technique introduced by Ye and Rabiller (Ye and Rabiller, 2000) known as MRGC (Multi-Resolution Graph-based Clustering) was tested and applied successfully for MICP curve classification. MRGC is a multi dimensional dot-pattern-recognition method based on non parametric K-Nearest-Neighbor (KNN) and graph data representation. KNN classification which is based on Euclidean distance between a test sample and the specified training samples is one of the first choices for a classification when there is little or no prior knowledge about the distribution of the data. KNN classification was developed from the need to perform discriminant analysis when reliable parametric estimates of probability densities are unknown or difficult to determine. Methods based on graph theory first constructs a connected graph where data points are linked by arcs according to their proximity relationship (Ye and Rabiller, 2000).

Applying MRGC, the underlying structure of the data is analyzed, and natural data groups are formed that may have very different densities, sizes, shapes, and relative separations. MRGC automatically determines the optimal number of clusters, yet allows the geologist to control the level of detail actually needed to define the Electro-Facies (Ye and Rabiller, 2000). It must be noted that it is not the method of clustering which is important but the performance of that method for target data set. Since performance of MRGC in classifying MICP curves was better that other clustering methods tested in this study such as Dynamic Clustering, Self Organizing Maps and Ascendant Hierarchal Clustering we decided to use this method. In addition this method is flexible when merging or splitting the clusters.

From 20 parameters derived from MICP curves (figure 5) 14 of them, with better correlation with permeability, were selected for cluster analysis. These parameters and their mean values for each cluster are listed in Table 1. An important decision in any clustering practices is the number of clusters. In this study, based on petrographical analysis, 9 representative clusters were identified. This approach is also to some degrees subjective and the geologist may decide for example to merge cluster\#4 and 6 or split them. As the number of clusters increases the accuracy of assigning average curves will be better but the number of samples and confidence with master curve will be decreased. 
As illustrated in figure 6, we successfully subdivided the MICP curves into discrete classes using this method. The similarity of the MICP curves in clusters is relative rather than absolute. In fact it is not possible to find two MICP curves which are exactly similar however classifying the curves into 231 categories is also impossible. What practically can be done is to classify the similar curves in one category but of course there will be some differences among the curves in one cluster. For each cluster the mean representative curve is also shown. This master curve has been determined directly by averaging the PC curves in that cluster. Using traditional facies definitions, it is necessary at first to convert the PC to J-Function. Each class represents different pore characteristics and hence different petrophysical properties. Each class label that is a number from 1 to 9 is a categorical variable in which the number has not any absolute value but each number is representative of different pore geometry.

Using the procedure illustrated in the above sections including MICP curve parameterization and classification, a qualitative parameter like pore geometry is represented by a quantitative variable. The following section will explain the phases of static modeling in which this quantitative variable can be used.

\section{Traditional Facies analysis and rock typing}

Quantification of pore geometry is a first step of incorporation of dynamic data into static models. But the next question is that, how and in which phases of static modeling, this number can be implemented. The answer will be demonstrated in the following discussion on facies analysis and reservoir rock typing.

There is not a unique definition for rock typing and most of the times it has been used interchangeably with facies analysis. Sometimes it refers to lithological properties, and in some literatures refers to petrophysical properties and sometimes the characteristic of pore body is the subject of rock typing. To be distinguished, here, we use the terms Reservoir Rock Type and Facies Analysis as an arbiters of reservoir engineers and geologists respectively.

Facies analysis: a facies could be defined as interval/intervals of reservoir which could be differentiated from nearby's based on one or more properties of reservoir rock. Reservoir geologists use various facies definitions for reservoir description. Most of the time the methodology and data accessibility dictates the facies model. Litho-Facies and Electro-Facies are amongst the most commonly used and applicable facies definitions. Litho-facies analysis relies on lithological and textural descriptions of the rock and by definition requires the observation of actual rock samples in the form of core description or thin section studies. An electro-facies corresponds to a cluster of closely spaced points that have similar log responses with the aim of presenting a set of $\mathrm{n} \log$ readings at a given depth level as a point in n-dimensional space (Serra and Abbott, 1982; Serra, 1986, Davis, 1986; Doveton, 1994; Tabachnick and Fidell, 1996). In some literatures the term rock fabric that refers to the geologic description of particle size and sorting based on the assumption that pore-size distribution is related to rock fabric and controls permeability and saturation is also used (Lucia, 1983, 1995). Each facies is assigned a 
number that doesn't has any absolute meaning however they may be sorted according to reservoir quality. For some facies definitions it is also possible to have a lithologic or reservoir quality description (Litho-Facies).

Reservoir rock typing is a process of classifying reservoir rocks into distinct units. From geological point of view, it is characterized by similar geological conditions, deposited in the same sedimentary environment and undergone through similar diagenetic alterations. From the reservoir engineering point of view it is characterized by similar fluid flow properties. Based on this definition, given rock type is imprinted by a unique permeabilityporosity relationship, capillary pressure profile (or J function), and set of relative permeability curves. In another word, a reservoir rock type is an interval of rock characterized by unique pore geometry (not necessarily a unique pore type). For each rock type the dominant pore type will be taken into account. In terms of reservoir modeling, each reservoir rock type is a class of facies characterized by the same relative permeability, capillarity and fluid saturations.

The industry accepted approach for reservoir rock typing, starts from facies analysis, which is usually done by reservoir geologist. Then it is tried to assign one capillary pressure and relative permeability curve to each facies. This part of basic reservoir engineering, is usually done by reservoir engineer. This procedure of facies analysis and reservoir rock typing causes serious problems in both static and dynamic reservoir models.

The fundamental controlling phenomena for nearly all of petrophysical properties is the quantity, shape, size, type and connectivity of the pore system, i.e. the pore characteristics of the rock. The implicit assumption beyond all facies models are that, they can be, somehow linked to pore characteristics but this link is not so straightforward and most facies definitions, fail to do so. There are some problems and hence source of error with traditional facies analysis and rock typing.

The first problem arises from traditional facies definition itself because most of the facies models are based on characteristics of solid framework of the rock, while reservoir rock type is identified based on parameters of pore space of the rock. Litho-Facies analysis relies heavily on lithological and textural description of the rock matrix. It is necessary to remember that in our sampling of formations, we are observing the sum of the various processes that affected the rocks from their initial creation through their particular burial history to their present-day depth and state of diagenetic alterations. It is this combined effect that gives rise to the observation that, commonly, subdivisions of formations based upon solely lithostratigraphic criteria frequently fail to capture the petrophysical variability of the rock adequately.

In Electro-Facies analysis the properties of interest could be the basic formation properties that we seek to measure in petrophysical analyses, like, density, resistivity, hydrogen index, acoustic travel time, nuclear magnetic resonance etc., or they might be the formation parameters such as porosity, permeability, capillarity and fluid saturation. The problem here is that, most of the times, the link between measured log and desired reservoir property is poorly defined, especially this is the case with pore geometry.

The second problem with traditional facies analysis is that, Litho-Facies and Electro-Facies analysis, just classifying the reservoir rock without taking into account any dynamic properties such as capillarity, relative 
permeability or wettability of the rock. From the reservoir modeling point of view, most facies definitions are based on static properties such as porosity and facies, while reservoir rock type is based on dynamic properties.

The third problem associated with traditional facies analysis arises from the averaging of each petrophysical properties for each facies. Since the samples falling into a specific cluster have a wide range of petrophysical properties, the high and low values which are especially important from the reservoir dynamics point of view, will over or underestimated.

The fourth problem with traditional facies analysis is the procedure with rock typing. Generally after Litho-Facies or Electro-Facies analysis and identification of representative number of facies, it is tried to assign one capillary pressure curve to each facies. For assignment of capillary pressure curve to each facies it is necessary at first to average the corresponding capillary pressure curves of each facies. The problem here is that, MICP curves with varying range of pore characteristics will be averaged. These problems will be further illustrated in the following sections.

Another problem with traditional facies analysis is the subjective nature of facies analysis. Any facies analysis is to some degree subjective and always there will be some differences among the vintages of facies classification performed by different reservoir geologists. Electro-Facies as an example is highly dependent on clustering method in that various clustering techniques result in different size and cluster numbers. The number of Litho-Facies defined depends on level of details considered in thin section study or core description; it is possible to do the subdivision of the reservoir rock exactly based on Dunham rock classification or to define some intermediate facies such as packstone/wackstone. This problem which arises from the nature of these facies definitions can only be partly handled (in terms of the number of clusters and assignment of reservoir quality indexes) considering some petrophysical measurements (usually porosity and permeability). Pore facies as mentioned earlier is also to some degree subjective however since this facies definition is based on pore geometry, finding the number of clusters and defining the reservoir quality of each facies is much easier and it doesn't require further data or analysis.

\section{Pore-Facies, a new method for facies analysis and direct rock typing}

Grotsch and Mercadier (1999) used a petrophysically-based definition of reservoir rock types (RRT) for their reservoir model input because of the nonlinear relationship between porosity and permeability in the Malampaya-Camago reservoir. Each RRT was characterized by its pore geometry, an average porosity, an average permeability, an average gas saturation, and a saturation-height function, but not necessarily by its Litho-Facies. Emphasis was on pore geometry, pore throat connectivity and core-derived permeability cutoffs.

This work by Grotsch and Mercadier is an example of the next group of facies analysis in which the petrophysical properties of the reservoir rock is the main focus of the interpretation and we call them with the general term of Petro-Facies. Petro-Facies analysis is defined as the characterization and classification of pore types and fluid saturations as revealed by petrophysical measurements of a reservoir. The word Petro-Facies 
makes an explicit link between petroleum engineers concerns with pore characteristics as arbiters of production performance and the facies paradigm of geologists as a methodology for genetic understanding and prediction (Watney, 1999). Most of the times the contrasts between reservoir pore types and fluid saturations are reflected in changing patterns on the cross-plot of various properties extracted from well logs or measured on core samples, and can help discriminate and characterize reservoir heterogeneity. Petro-Facies analysis always is applied to distinguish flow units and including discriminating pore type as an assessment of reservoir conformance and continuity.

Petro-Facies is a general term which may range from facies defined based on porosity-permeability crossplot to those which are defined based on pore geometry. In this study the facies are defined according to pore characteristics i.e. pore type and pore geometry and hence the facies defined based on this method is called PoreFacies. To describe the Pore-Facies, each cell of reservoir rock could be visualized as two distinct parts, the solid framework, or matrix, and the pores.

It was demonstrated that pore geometry can be quantified using MICP curves. Hence we can come to this conclusion that, it is possible to do Pore-Facies analysis and direct rock typing using MICP curves. A sample of Litho-Facies analysis may be a thin section or a sample of core and a sample of Electro-Facies is various $\log$ readings at specific depth. However, a sample of Pore-Facies is a MICP curve. Each MICP curve after parameterization and classification will fall into one of the clusters which is characterized and identified from the other clusters, based on pore geometrical parameters, and since each cluster has a meaningful distribution of petrophysical properties we call it Pore-Facies. This facies can be treated like other facies definitions and can be used for facies modeling. figure 7 illustrates an example of thin section photomicrograph for Pore-Facies identified in this study with corresponding capillary pressure curve and pore throat size distribution. Pore-Facies in this figure are sorted with decreasing reservoir quality and as it can be inferred this new defined facies does not comply with Litho-Facies. As illustrated in this figure each facies has a distinct MICP curve. The corresponding petrophysical properties and main parameters extracted from MICP curves are listed in Table 2.

\section{Preparing the facies for incorporation into reservoir model}

The final step in every facies definition at cored sections is to average the parameters of samples falling into one cluster. The same procedure is applied for Pore-Facies analysis. In most geological modeling packages, facies model act as a constraint for petrophysical models, i.e. after population of facies through the reservoir, petrophysical properties are assigned to each cell of the model in such a way that the values of these properties will range between minimum and maximum values of corresponding properties in each facies. It is possible to create histogram of porosity, permeability and other petrophysical properties such as water saturation, and net/gross ratio. These values will be later propagated through the reservoir using geostatistical methods.

After averaging the petrophysical properties for each facies, the corresponding capillary pressure will be assigned. The capillary pressure curves for rock samples from the same reservoir having different permeabilities 
will be different. It is often necessary to average the capillary pressure data for cores believed to have the same pore structure in order to obtain one capillary pressure curve that can be used for reservoir performance analysis. A method for averaging capillary pressure data from various systems is the use of the Leverett $\mathrm{J}$ function (Leverett, 1941). Leverett proposed the J-function of a specific reservoir which describes the heterogeneous rock characteristics, more adequately by combining porosity and permeability in a parameter for correlation. The Jfunction accounts for changes of permeability, porosity, and wettability of the reservoir as long as the general pore geometry remains constant. Therefore, different types of rocks exhibit different J-function correlations. All of the capillary pressure data from a specific formation usually can be reduced to a single J-function versus the saturation curve (Tiab et al., 2004). It is a dimensionless capillary pressure function and can be expressed as:

$$
J=\frac{C \cdot P c}{\sigma \cos \theta} \cdot \sqrt{\frac{k}{\phi}}
$$

where $\mathrm{J}$ is Leverett capillary pressure function (dimensionless), $\mathrm{Pc}$ is capillary pressure in $\mathrm{kPa}, \sigma$ is airmercury interfacial tension, $0.0485 \mathrm{kPa}\left(485\right.$ dynes $\left./ \mathrm{cm}^{2}\right), \theta$ is air-mercury contact angle, degrees (140), $\mathrm{k}$ is permeability in $\mathrm{md}, \phi$ is porosity (fraction) and $\mathrm{C}$ is the unit conversion constant.

The J-function has the effect of normalizing all curves to approach a single curve and is based on the assumption that the porous medium can be modeled as a bundle of non-connecting capillaries. Obviously the more capillary bundle assumption deviates from reality, the less effective the J-function correlation becomes. Porous media that have the same pore structure but different permeability and porosity will have the same Leverett J-function. If the porous media have different pore structures, then the Leverett J-functions for the different rocks will be different and will not plot as one curve (figure 8).

One important improvement of Pore-Facies over the traditional facies definitions is that, finding the representative MICP curve is straightforward, because all curves with the similar properties will fall into a single cluster. In fact using Pore-Facies it is possible to find the representative average PC curve directly, by averaging the MICP curves in each cluster and of course without using the J-Function. In addition Pore-Facies has several advantages and improvements over J-Function and overcomes some of the main limitations of this method as listed below:

1- The basic assumption beyond the J-Function is that the porous medium can be modeled as a bundle of non-connecting capillaries and any deviation from such assumption, less effective the J-Function will be (Slider, 1983). Using the Pore-Facies approach it is not necessary to assume a certain theoretical model because it is based on real reservoir samples.

2- When the MICP curves are in different shape and character the J-Function is used to bring the curves into a similar shape so that the averaging to be possible. This procedure of averaging causes some errors to be included into the reservoir model. Using Pore-Facies MICP curves with similar shape and signature and hence similar pore geometry will be grouped into one single cluster and so this method is inherently innocent of the problems associated with J-Function. 
3- As indicated in equation 11, for application of J-Function the respective porosity and permeability of the sample shall be given, but this is not the case with Pore-Facies.

\section{Results and discussion}

To compare different facies definitions and for illustration of advantage and limitation of each method, ElectroFacies and Litho-Facies analysis were also conducted on samples.

Thin section description was done on 400 samples from 3 cored wells. The samples assessed for texture, grain size, composition, cements, grain types and pore types. All samples were found to comprise almost entirely limestone. Dolomite occurs in some samples but rarely exceeds 1\%. Dunham classification was used for LithoFacies definition and it was found that there are eight main Litho-Facies as follow: boundstone, floatstone, rudstone, grainstone, packstone, packstone/wackstone, wackstone and mudstone. Electro-Facies were defined by cluster analysis on Gamm Ray, Density, Sonic and Neutron Porosity logs and with the assumption that the number of facies to be 9 .

Comparison among different facies definition has been done based on 2 criteria: a) Ability of the methods for classification of MICP curves into meaningful clusters; b) standard deviation of permeability and sensitivity of each facies definition to permeability variation.

a) MICP curve classification: figure 9 shows the result of clustering using MRGC on cross-plot of Sonic, Gamma Ray, Neutron Porosity and Density. As it is visible, all facies are clearly well separated and it may be regarded as good clustering. However this clustering would not necessarily warranty the optimum classification of MICP curves. Figure 10 and 11 show the results of MICP curve clustering using Litho-Facies and ElectroFacies respectively. As illustrated in both cases, curves with varying shape and signature and hence with different pore geometry and dynamic properties have been categorized into the same cluster. Figures 6,10 and 11 show the results of MICP curve clustering using Pore-Facies, Litho-Facies and Electro-Facies respectively. As illustrated in these figures, while the MICP curves are well separated using Pore-Facies, there is a lot of overlap on clusters of Litho and Electro-Facies. Obviously this misclassification will affect both static and dynamic reservoir models. It can be concluded that while electro-facies and litho-facies are good facies classification approach, they are not necessarily appropriate rock typing methods.

b) Permeability: Carbonates are characterized by different types of porosity. They have unimodal, bimodal and other complex pore size distributions; this is why it is concerned about trying to extract the various parameters from the curves. That would results in wide permeability variations for the same total porosity which makes prediction of producibility very difficult. Numerous ways of calculating permeability from wireline logs have been tried. The most popular has been the porosity-permeability transform in the clusters of facies. A comparison among various facies definitions of Pore-Facies, Electro-Facies and Litho-Facies has been made in figure 12. This figure shows the mean (squares) and the standard deviation of permeability for each facies within different facies definitions. This figure shows that facies definitions based on Pore-Facies for permeability works 
much better than Electro-Facies and Litho-Facies. The consequence of this smaller standard deviation will be reflected in smaller range of uncertainty in any permeability modeling which is constraint by facies.

One important step in every facies analysis is the prediction of facies in in-cored wells based on commonly available data which is usually wireline logs. Pore-facies in this regard is similar to other facies definitions and it is possible to test and apply among the variety of proposed approaches. For example multivariate statistical techniques for electro-facies analysis have been applied by many workers to both clastic and carbonate reservoirs (e.g., Serra and Abbott, 1982; Widdicombe et al 1984; Serra et al 1985; Busch et al 1985 Delfiner et al 1987; Sakurai and Melvin, 1988; Stowe and Hock, 1988; Anxionnaz et al 1990; Murray, 1994; Hook et al 1994; Elphick et al 1996) Several techniques have been reported for litho-Facies prediction; Wolff and Pelissier-Combescure (1982) used principal component analysis, Delfiner et al (1987) used discriminant factor analysis, Methods relying on self-organizing maps (Baldwin et al 1990) and backpropagation feed forward neural networks (Rogers et al 1992) were also used for the estimation of litho-facies from logs. Toumani et al (1994) used fuzzy clustering to determine lithology from well logs and Cuddy (1997) used fuzzy logic to predict permeability and lithofacies in uncored wells. Saggaf et al (2000) used neural networks for identifying both lithological and depositional facies from well logs and Saggaf and Nebrija (2003) used a method based on fuzzy logic inference to identify lithological and depositional facies from wire-line logs. Several authors have used soft computing techniques for estimation of permeability (Huang et al., 1996, Cuddy, 1997, Fang and Chen, 1997, Huang et al., 1999, Kadkhodaie et al., 2006). In this study, to examine the suitability of pore-facies approach, the MRGC clustering method has been applied for the subdivision of the data space into 9 representative pore-facies and the corresponding relationships between porosity and permeability for each facies has been determined. After identification of the main responsive well log suite, based on the rank correlation, a classification tree approach was used for the population of pore-facies in the un-cored wells. Then applying the relevant porosity-permeability relation, permeability was calculated. The sensitivity of Pore-Facies, Electro-Facies and Litho-Facies to permeability variations are displayed in figure 13. In this figure the first track is GR, the second and third tracks display formation and reservoir zonation respectively. Tracks 4-6 are PoreFacies, Electro-Facies and Litho-Facies respectively. The blocked curves in these three tracks are measured permeability. As shown in this figure, any real variation in permeability is reflected in Pore-Facies; however this is not the case for the Electro and Litho-Facies. The conclusion here is that Pore-Facies which is based on pore geometry among the various facies definitions is the preferred approach for permeability prediction.

Because of these advantages it is recommended that, for MICP curve averaging in the next reservoir modeling practices or in any refinement to previous models, the Pore-Facies approach introduced in this study to be applied. 


\section{Summary}

1- Incorporation of dynamic data into static model reduces the uncertainty associated both in static and dynamic reservoir models. It is possible to incorporate dynamic data in all scales and all stages of integrated reservoir studies.

2- Pore geometry is a controlling parameter for most of petrophysical properties and small scale reservoir heterogeneities. With the incorporation of this parameter in reservoir model, most of petrophysical properties are considered.

3- Pore geometry is a qualitative parameter. To include this parameter into a reservoir model it should be represented quantitatively. Petrography, mercury injection capillary pressure (MICP), image analysis, and nuclear magnetic resonance (NMR) provide quantitative pore-geometry parameters. In general, among the various techniques, MICP has the widest application and can handle more attributes than any other technique.

4- For quantification of pore geometry, the first step is to obtain some parameters from MICP curves (parameterization) and the next step is classification of these curves into meaningful clusters.

5- One approach for parameterization of MICP curves might be to get pressure (or pore throat size) equivalent of different water saturations. An alternative approach would be to extract some parameters which are related to pore characteristics via some theoretical or empirical relations. The first approach comprises the capillary models and second approach includes parameters like, threshold pressure, pore throat radius, reservoir grade, pore throat size distribution, pore throat sorting, mean hydraulic radius, etc.

6- After parameterization of MICP curves, numerical data, i.e. parameters extracted from MICP curves will be used to classify the curves into a meaningful clusters to get a discrete variable i.e. facies, that can later be used in facies modeling. By applying the procedure including MICP curve parameterization and classification, a qualitative parameter like pore geometry will be represented by a quantitative variable. Result of MICP curve quantification is a discrete variable in which each curve or sample will be represented by a categorical number.

7- Quantified pore geometrical properties which are discrete variables, similar to any facies definition, can be used for facies modeling. Since the new definition of facies is based on pore characteristics, it is called PoreFacies. While the conventional facies definitions are based on solid part of the reservoir rock, Pore-Facies relay primarily on porous part of the rock and specifically pore geometry.

8- Dependency of dynamic reservoir rock properties into pore geometry makes the Pore-Facies as an interesting and powerful approach for incorporation of small scale dynamic data and heterogeneity into reservoir model.

9- Different facies definitions i.e. Litho-Facies, Electro-Facies and Pore-Facies could be compared based on: ability of these methods for classification of MICP curves into meaningful clusters, standard deviation of permeability within each facies definition and sensitivity of each facies definition to permeability variation. Comparison of various facies definitions shows that Pore-Facies has the best performance for classification of MICP curves into meaningful cluster and has the smallest standard deviation of permeability within each class. 
10- Pore-Facies can be used, instead of Leverett J-Function, as an improved method of MICP curve averaging. This approach not only overcomes the limitation of traditional method of PC curve averaging (JFunction), i.e. requirement of porosity and permeability, but also by classifying the MICP curves into meaningful clusters, improves the selection of representative PC curve.

11- The next generation of the reservoir models which incorporate Pore-Facies based rock types, will provide a basis for more accurate static and dynamic models, a narrower range of uncertainty in the models, and a better prediction of reservoir performance while avoiding misclassification of rock types and integrating dynamic data in to static reservoir models. 


\section{References}

Anxionnaz, H., Delfiner, P., Delhomme, J.P., 1990. Computer-generated core like descriptions from open-hole logs. AAPG, 74: 375-393.

Archie, G.E., 1942. The Electrical Resistivity Log as an Aid in Determining Some Reservoir Characteristics. Trans AIME, 146: 54-62.

Archie, G.E., 1952. Classification of Carbonate Reservoir Rocks and Petrophysical Considerations. AAPG, 36: 278-298.

Baldwin, J.L., Bateman, R.M., Wheatley, C.L., 1990. Application of a neural network to the problem of mineral identification from well logs. The Log Analyst, 3: 279-293.

Basan, P.B., Lowden, B.D., Whattler, P.R., Attard, J.J., 1997. Pore Size Data in Petrophysics: A Perspective on the Measurement of Pore Geometry. In: M.A. Lovell, P.K., Harvey (Editors), Development in Petrophysics, Geological Society Special Publication, 122, pp. 47-67.

Biot, M.A., 1953. General Solutions of The Equations of Elasticity And Consolidation for A Porous Material. J. Appl. Mech., 23: 91-96.

Bos, M.R.E., 1982. Prolific Dry Oil Production From Sands With Water Saturation In Excess Of 50\%: A Study Of A Dual Porosity System. The Log Analyst, 23 (5): 17-23.

Brooks, R.H., Corey, A.T., 1966. Properties of Porous Media Affecting Fluid Flow. Journal of Irrigation and Drainage Division. ASCE, 92: 61-88.

Brown, R.J.S., Gamson, B.W., 1960. Nuclear Magnetism Logging. JPT, 12: 199-201.

Brownstein, K.R., Tarr, C.E., 1979. Importance of Classical Diffusion in NMR studies of Water in Biological Cells. Physics Reviews A, 19: 2446-2453.

Burdine, N.T., Gournay, L.S., Reichertz, P.P., 1950. Pore Size Distribution of Petroleum Reservoir Rocks. Trans. AIME, 189: 195-204.

Busch, J.M., Fortney, W.G., Berry, L.N., 1985. Determination of lithology from well logs by statistical analysis. SPE Paper 14301.

Calhoun, J.C., Lewis, M., Newman, R.C., 1949. Experiments on the Capillary Properties of Porous Solids. Trans. AIME, 186: 189-196.

Choquette, P.W. and L.C. Pray, 1970. Geologic Nomenclature and Classification of Porosity in Sedimentary Carbonates. AAPG, 54: 207-250.

Corey, A.T., 1954. The Interrelation between Gas and Oil Relative Permeabilities. Prod. Mon., 19: 38-41

Cosentino, L., 2001. Integrated Reservoir Studies. Editions Technip, Paris, 310 pp.

Cuddy, S.J., 1997. The Application of Fuzzy Logic to Petrophysics. Society of Professional Well Log Analysts $28^{\text {th }}$ Annual Logging Symposium Transactions.

Davis, J.C., 1986. Statistics and data analysis in geology, New York, John Wiley and Sons, 646 p.

Delfiner, P., Peyret, O., Serra, O., 1987. Automatic determination of lithology from well logs. SPE Formation Evaluation, 2: 303-310.

Doligez, B., Beucher, H., Geffroy, F., Eschard, R., 1999. Integrated Reservoir Characterization: Improvement in Heterogeneous Stochastic Modeling by Integration of Additional External Constraints. In: R. 
Schatzinger, J. Jordan, (Editors), Reservoir Characterization-Recent Advances. AAPG Memoir 71: 333342.

Donaldson, E.C., Ewall, N., Singh, B., 1991. Characteristics of Capillary Pressure Curves. Journal of Petroleum Science and Engineering, 6: 249-261.

Doveton, J.H., 1994. Geologic log analysis using computer methods. AAPG Computer Applications in Geology No. 2, 169 p.

Dunham, R.J., 1962. Classification of Carbonate Rocks According to Their Depositional Texture. In: W. E. Ham, Classification of Carbonate Rocks. AAPG Memoir 1: 108-121.

Ehrlich, R., Crabtree, S.J., Horkoswitz, K.O., Horkoswitz, J.P., 1991. Petrography and Reservoir Physics 1: Objective Classification of Reservoir Porosity. AAPG, 75: 1547-1562.

Ehrlich, R., Crabtree, S.J., Horkoswitz, K.O., Horkoswitz, J.P., 1984. 1. Petrographic Image Analysis of Reservoir Pore Complexes, Journal of Sedimentary Petrology, 54: 1365-1378.

Elphick, R.Y., Carr, D.L., Johns, R.A., Lancaster, D.E., 1996. A deterministic method for calculating facies from wire line logs. The Log Analyst, 37: 14-25.

Fang, J.H., Chen, H.C., 1997. Fuzzy modeling and the prediction of porosity and permeability from the compositional and textural attributes of sandstone. Journal of Petroleum Geology, 20: 185-204.

Grotsch, J., Mercadier, C., 1999. Integrated 3-D Reservoir Modeling Based on 3-D Seismic: The Tertiary Malampaya and Camago buildups, offshore Palawan, Philippines. AAPG, 83: 1703-1728.

Hook, J.R., Nieto, J.A., Kalkomey, C.T., Ellis, D., 1994. Facies and permeability prediction from wireline logs and cores - a north sea case. Society of Professional Well Log Analysts 35th annual logging symposium, paper AAA.

Huang, Z.J., M.W., Shimeld, Katsube, J., 1996. Permeability prediction with artificial neural network modeling in the Venture gas field offshore eastern Canada. Geophysics, 61: 422-436.

Huang, Y., Gedeon, T.D., Wong, P.M., 1999. A practical fuzzy interpolator for prediction of reservoir permeability: Proceeding of Institute of Electrical and Electronics Engineers International Conference on Fuzzy Systems, Seoul, South Korea, pp. III-1528-III-1533.

Huet, C.C., Rushing, J.A., Newsham K.E, Blasingame, T.A., 2005. A Modified Purcell/Burdine Model for Estimating Absolute Permeability from Mercury-Injection Capillary Pressure Data. International Petroleum Technology Conference, Doha, Qatar, 21-23 November, IPTC 10994..

Jackson, P.D., Taylor S.D., Stanford, P.N., 1978. Resistivity-Porosity-Particle Shape Relationships for Marine Sands. Geophysics, 43 (6): 1250-1268.

Jing, X.D. and Van Wunnik, J.N.M., 1998. A Capillary Pressure Function for Interpretation of Core Scale Displacement Experiments. Proceedings of International Symposium of the Society of Core Analysts, The Hague, Netherlands, Sept. 14-16, SCA 9807.

Kadkhodaie Ilkhchi, A., Rezaee, M.R., Moallemi, S.A., 2006. A fuzzy logic approach for estimation of permeability and rock type from conventional well log data: an example from the Kangan reservoir in the Iran offshore gas field. Journal Of Geophysics And Engineering, 3: 356-369.

Lenormand, R., 1990. Gravity-Assisted Inert Gas Injection: Micromodel Experiments and Model Based on Fractal Roughness. European Oil and Gas Conference, Altavilla Milica, Palermo, Sicily, October 9-12.

Leverett, M. C., 1941. Capillary Behavior in Porous Solids. Trans. AIME, 142: 152-169. 
Li, K. and Horne, R.N., 2002. Experimental Verification of Methods to Calculate Relative Permeability Using Capillary Pressure Data. SPE Western Regional/ AAGP Pacific Section Joint Meeting, Anchorage, AK, May 20 - 22, Paper SPE 76757

Lønøy, A., 2006. Making Sense of Carbonate Pore Systems, AAPG, 90 (9): 1381-1405.

Lucia, F.J., 1983. Petrophysical Parameters Estimated from Visual Descriptions of Carbonate Rocks: A Field Classification Of Carbonate Pore Space. JPT, 35: 629-637.

Lucia, F.J., 1995. b, Rock-Fabric/Petrophysical Classification of Carbonate Pore Space For Reservoir Characterization. AAPG, 79: 1275-1300.

Lucia, F.J., 1999. Carbonate Reservoir Characterization. Springer Verlag, Berlin Heidelberg, 226 pp.

Martin F.D., Kendall R.P., Whitney, E.M., Hardage, B.A., Stubbs, B.A., Uszynski, B., Weiss, W.W., 1999. Advanced Reservoir Characterization for Improved Oil Recovery in a New Mexico Delaware basin project. In: R. Schatzinger, J. Jordan, (Editors), Reservoir Characterization-Recent Advances. AAPG Memoir 71: 93-108.

Morgan, J.T., Gordon, D.T., 1970. Influence of Pore Geometry on Water-Oil Relative Permeability, JPT, 22: 1199-1208.

Murray, C.J., 1994. Identification and 3-D modeling of petrophysical rock types in stochastic modeling and geostatistics: principles, methods, and case studies in J.M. Yarus, Chambers, R.L., eds., AAPG Computer Applications in Geology, p. 323-337.

Purcell, W. R., 1949. Capillary Pressures: Their Measurement Using Mercury and the Calculation of Permeability There from. Trans. AIME, 186: 39-48.

Rogers, S.J., Fang, J.H., Karr, C.L., Stanley, D.A., 1992. Determination of lithology from well logs using a neural network. AAPG Bulletin, 76: 731-739.

Rose, W., Bruce, W.A., 1949. Evaluation of Capillary Character in Petroleum Reservoir Rock. Trans. AIME, 186: $127-142$.

Saggaf, M.M., Nebrija, Ed.L., 2000. Estimation of lithologies and depositional facies from wire-line logs. AAPG Bulletin, 84: 1633-1646.

Saggaf, M.M., Nebrija, Ed.L., 2003. A fuzzy logic approach for the estimation of facies from wire-line logs: AAPG Bulletin, 87: 1223-1240.

Sakurai, A.H., Melvin, J., 1988. Facies discrimination and permeability estimation from well logs for the Endicott Field: Society of Professional Well Log Analysts, 29th Annual Logging Symposium Transactions, Paper FF.

Seevers, D.O. 1966. A Nuclear Magnetic Method for Determining the Permeability of Sandstones, SPWLA, $7^{\text {th }}$ Annual Logging Symposium, Tulsa, Oklahoma, USA, May 8-11 Paper L.

Seifert, D., Newbery, J.D.H., Ramsey, C., Lewis, J.J.M., 1999. Evaluation of field development plans using 3-D reservoir modeling,. In: R. Schatzinger, J. Jordan, (Editors), Reservoir Characterization-Recent Advances. AAPG Memoir 71, pp. 321-332.

Serra, O., Abbott, H., 1982. The Contribution of Logging Data to Sedimentology and Stratigraphy, SPE $55^{\text {th }}$ Annual Technology Conference, Paper SPE 9270.

Serra, O., 1986. Fundamentals of well-log interpretation, 2: The interpretation of logging data. Amsterdam, Elsevier Science Publishers, 684 p. 
Serra, O., P. Delfiner, and J. C. Levertt, 1985, Lithology determination from well logs: case studies Society of Professional Well Log Analysts $26^{\text {th }}$ Annual Logging Symposium Transactions, Paper WW.

Skelt, C.H. and Harrison, B., 1995. An Integrated Approach to Saturation Height Analysis., SPWLA $36^{\text {th }}$ Annual Symposium, June 26-29 Paper NNN.

Slider, H.C., 1983. Worldwide Practical Petroleum Reservoir Engineering Methods, Penwell Books.

Stowe, I., Hock, M., 1988. Facies analysis and diagenesis from well logs in the Zechstein carbonates of northern Germany. Society of Professional Well Log Analysts $29^{\text {th }}$ Annual Logging Symposium Transactios, Paper HH.

Swanson, B.F., 1981. A Simple Correlation between Permeabilities and Mercury Capillary Pressures, JPT, 33: 2488-2504.

Tabachnick, B.G., Fidell, L.S. 1996. Using multivariate statistics. New York: HarperCollins College Publishers, $880 \mathrm{p}$.

Tao, G., King, M.S., 1993. Porosity and Pore Structure from Acoustic Well Logging Data. Geophysical Prospecting, 41: 435-451.

Thomeer, J.H.M., 1960. Introduction of a Pore Geometrical Factor Defined by the Capillary Pressure Curve. Trans. AIME, 213: 354-358.

Thompson, A.H., Katz, A.J., Raschke, R.A., 1987. Estimation of Absolute Permeability from Capillary Pressure Measurements. SPE $62^{\text {nd }}$ Annual Technical Conference, Paper SPE-16794, pp. 475-481.

Tiab, D., Donaldson, E.C., 2004. Petrophysics: Theory and Practice of Measuring Reservoir Rock and Fluid Transport Properties, Elsevier, 889 pp.

Timur, A., 1969. Pulsed Nuclear Magnetic Resonance Studies of Porosity, Movable Fluid and Permeability. JPT, 21: 775-786.

Toumani, A., Schmitz, D., Schepers, R., 1994. Automatic determination of lithology from well logs using fuzzy classification. $56^{\text {th }}$ Meeting of the European Association of Exploration Geophysicists, paper H041.

Van de Graaff, W.J.E., Ealey, P.J., 1989. Geological modelling for simulation studies. AAPG, 73: 1436-1444.

Van Genuchten, M.Th., 1980. A Closed-Form Equation for Predicting the Hydraulic Conductivity of Unsaturated Soils. Soil Sci. Soc. Am. J., 44: 892-898.

Wardlaw, N.C., Taylor, R.P., 1976. Mercury Capillary Pressure Curves and The Interpretation of Pore Structure and Capillary Behavior in Reservoir Rocks. Bulletin of Canadian Petroleum Geology, 24: 225- 262.

Watney, W.L., Guy, W.J., Doveton, J.H., Bhattacharya, S., Gerlach, P.M., Bohling, G.C., Carr, T.R., 1999. Petrofacies Analysis: a Petrophysical Tool for Geologic-Engineering Reservoir Characterization. In: R. Schatzinger J., Jordan (Editors), Reservoir Characterization-Recent Advances. AAPG Memoir 71, pp. 73-90.

Wells, J.D., Amaefule, J.O., 1985. Capillary Pressure and Permeability Relationships in Tight Gas Sands. SPE 60th Annual Technical Conference, May 19-22, paper SPE 13879.

Widdicombe, R.E., Noon, P., Best, D.L., 1984. Multiwell faciolog evaluation, Hartzog Draw field, Power River Basin. Wyoming: Society of Professional Well Log Analysts $25^{\text {th }}$ Annual Logging Symposium Transactions, Paper BBB.

Wilkens, R., Simmons, G., Caruso, L., 1984. The Ratio Vp/Vs as a Discriminant of Composition for Siliceous Limestones, Geophysics, 49: 1850-1860. 
Wolff, M., Pelissier-Combescure, J., 1982. FACIOLOG, automatic electro-facies determination. Society of Professional Well Log Analysts $23^{\text {rd }}$ Annual Logging Symposium Transactions, paper FF.

Wyllie M.R., Spangler M.B., 1951. The Application of Electrical Resistivity Measurements to the Problem of Fluid Flow in Porous Media, Research Project 4-G-1 Geology Division Report No. 15, Gulf Research and Development Company.

Xu, S. and White, R.E. 1996. A Physical Model For Shear Wave Velocity Prediction. Geophysical Prospecting, 44: 687-717.

Xu, S. and White, R.E., 1995, A new velocity model for Clay-Sand Mixtures. Geophysical Prospecting, 43: $91-$ 118.

Ye, S.J., Rabiller, P., 2000. A New Tool for Electro-Facies analysis: Multi-Resolution Graph-based Clustering. SPWLA $41^{\text {st }}$ annual Logging Symposium, June 4-7. 


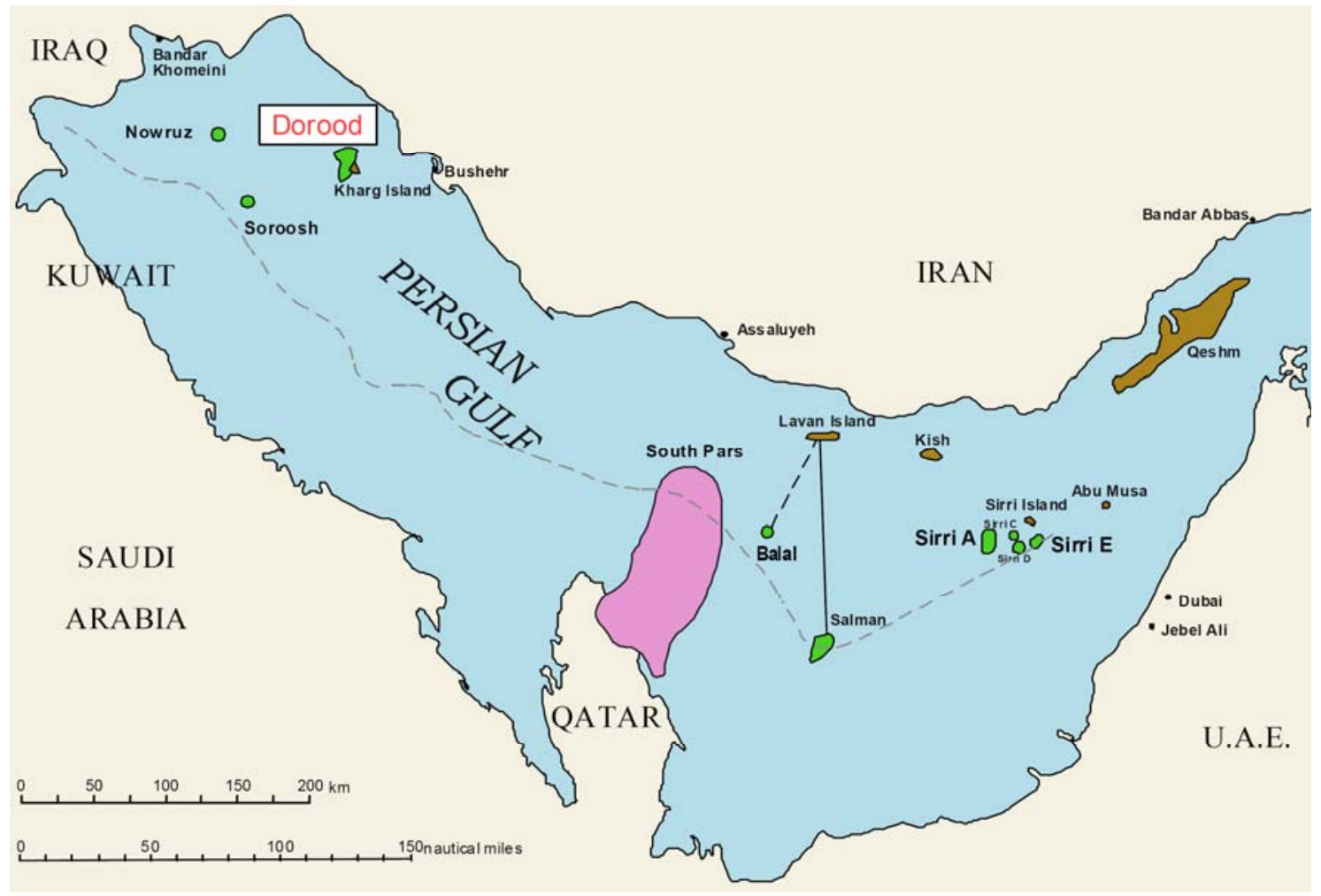

Figure 1 


\begin{tabular}{|c|c|c|c|c|}
\hline \multicolumn{2}{|c|}{ Chronostratigraphy } & Formation & Lithology & Layering \\
\hline \multirow{12}{*}{$\begin{array}{l}\text { Lower } \\
\text { Cretaceous }\end{array}$} & Barremian & Lower Gadvan & 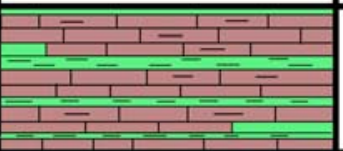 & \\
\hline & \multirow{8}{*}{ Valanginian } & Unper Yamama & 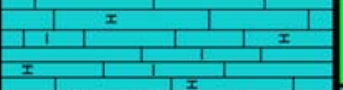 & $C D$ \\
\hline & & & ${ }_{1}^{1} y^{\prime}-1$ & E \\
\hline & & & \begin{tabular}{|l|l|l|l|} 
& 1 & \\
\end{tabular} & $F$ \\
\hline & & \multirow{8}{*}{ Middle Yamama } & \begin{tabular}{|l|l|l|l|l|l|l|}
1 & \\
&
\end{tabular} & G1 \\
\hline & & & $\begin{array}{l}1 \\
\end{array}$ & G2 \\
\hline & & & 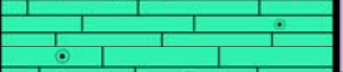 & $\mathrm{H} 1$ \\
\hline & & & \begin{tabular}{|l|l|l|l|l|l|l|l|l|l|} 
& \\
\end{tabular} & $\mathrm{H} 2$ \\
\hline & & & \begin{tabular}{l|l|l}
1 & 1 \\
\end{tabular} & I1 \\
\hline & \multirow{3}{*}{ Berriasian } & & \begin{tabular}{l|l|l} 
& $\bullet$ & \\
\end{tabular} & 12 \\
\hline & & & 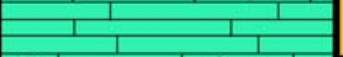 & $J$ \\
\hline & & & 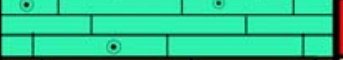 & K \\
\hline \multirow[b]{2}{*}{$\begin{array}{l}\text { Upper } \\
\text { Jurassic }\end{array}$} & \multirow[b]{2}{*}{ Tithonian } & Manifa & \begin{tabular}{ll|llll}
1 & 1 & 1 & 1 \\
\end{tabular} & $\mathrm{L1}$ \\
\hline & & Hith & 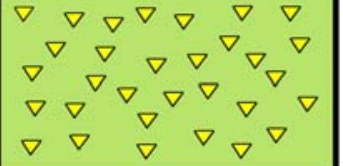 & \\
\hline
\end{tabular}

Figure 2 


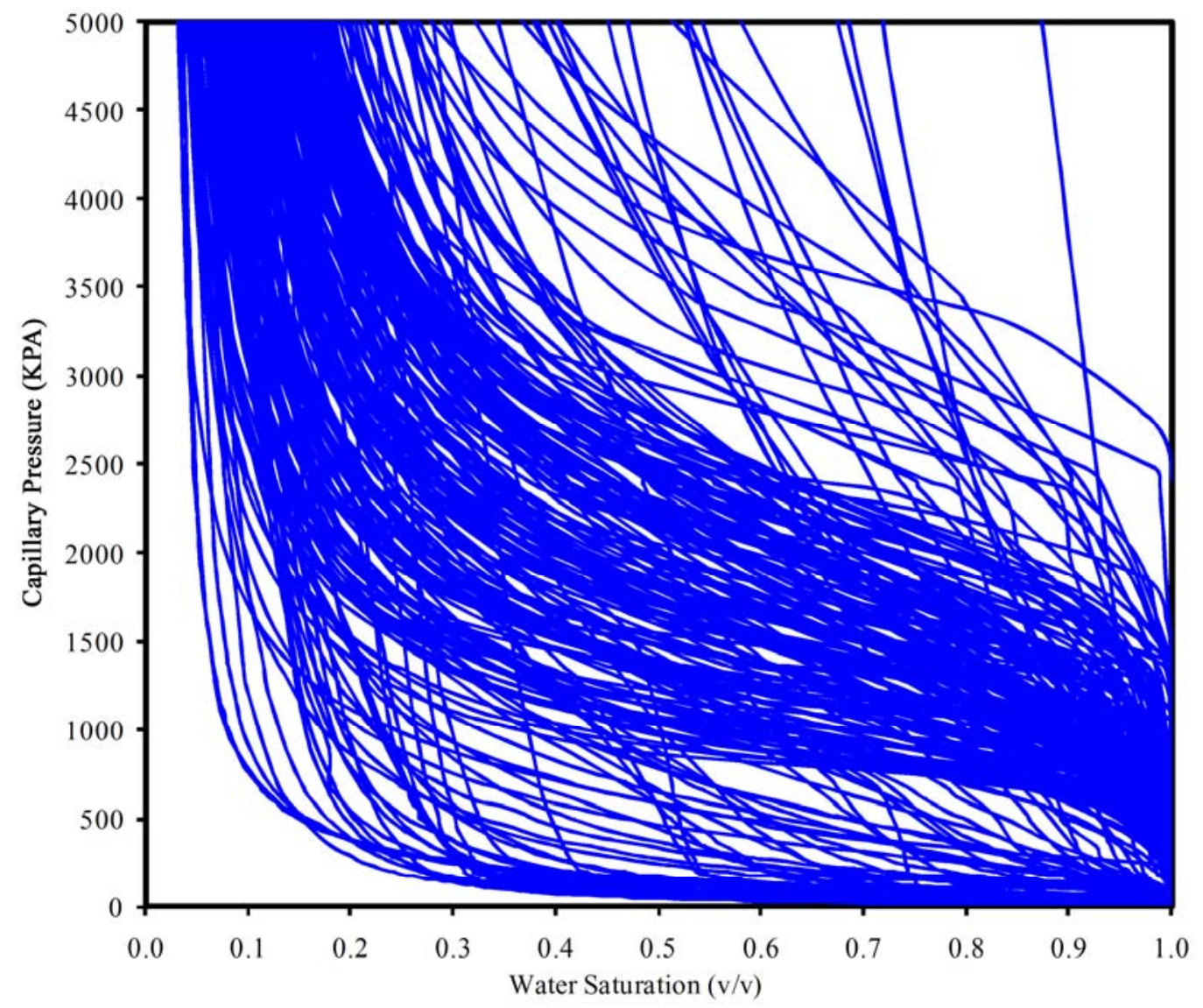

Figure 3 

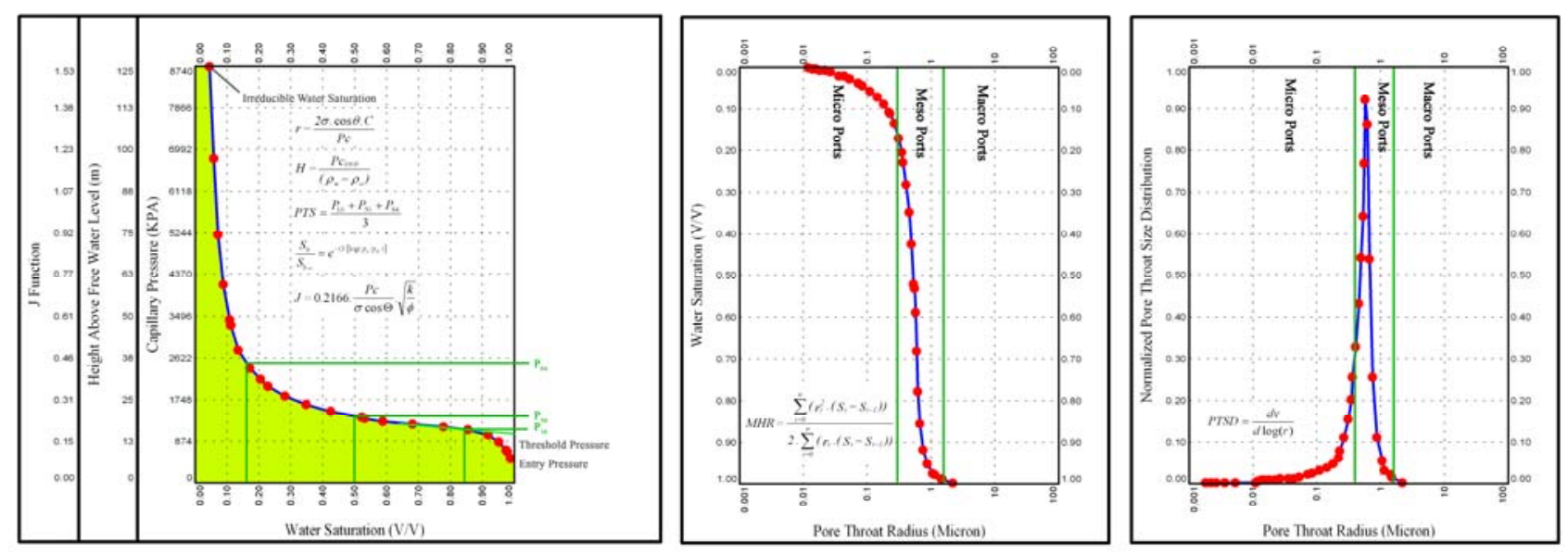

Figure 4 


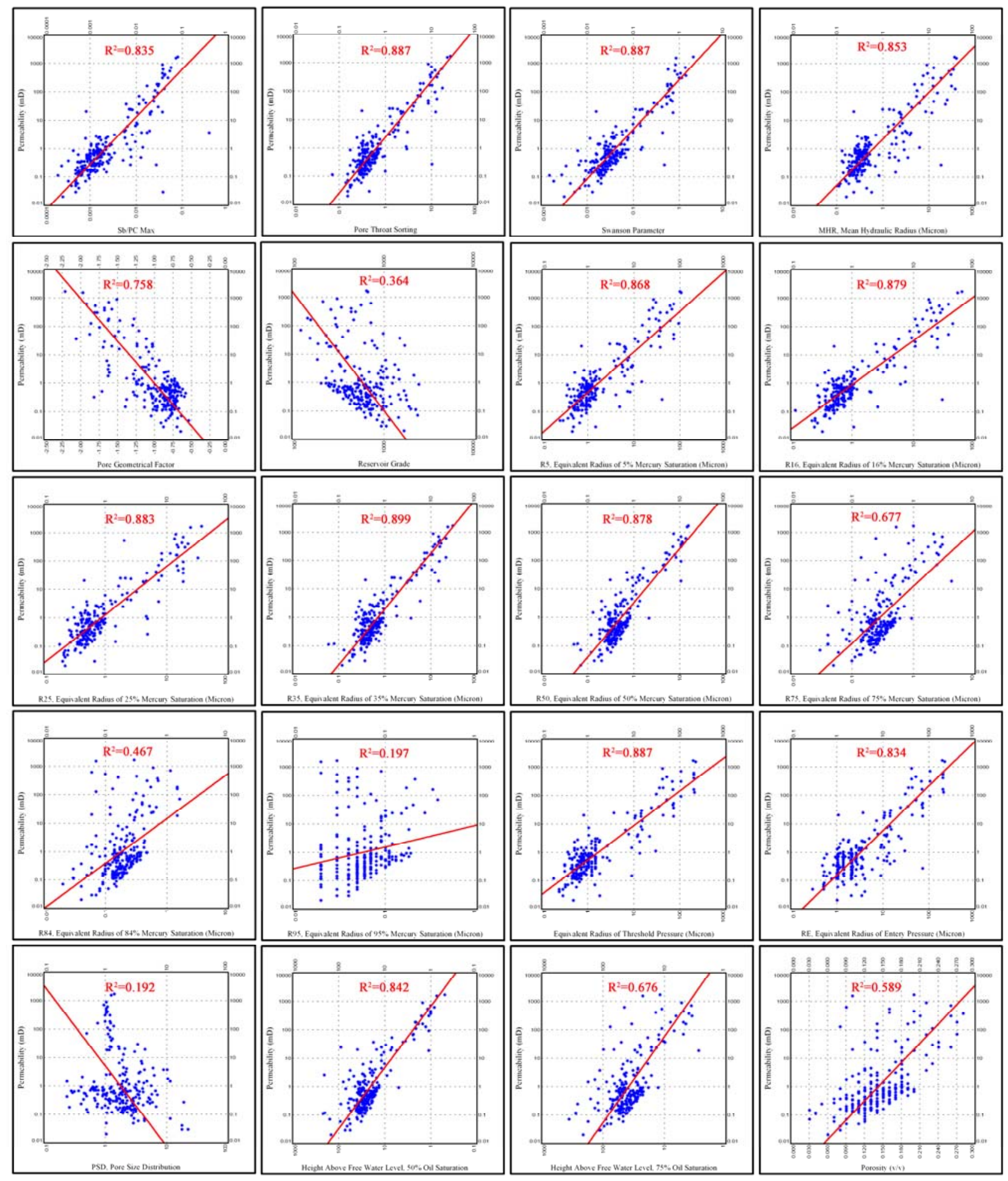

Figure 5 

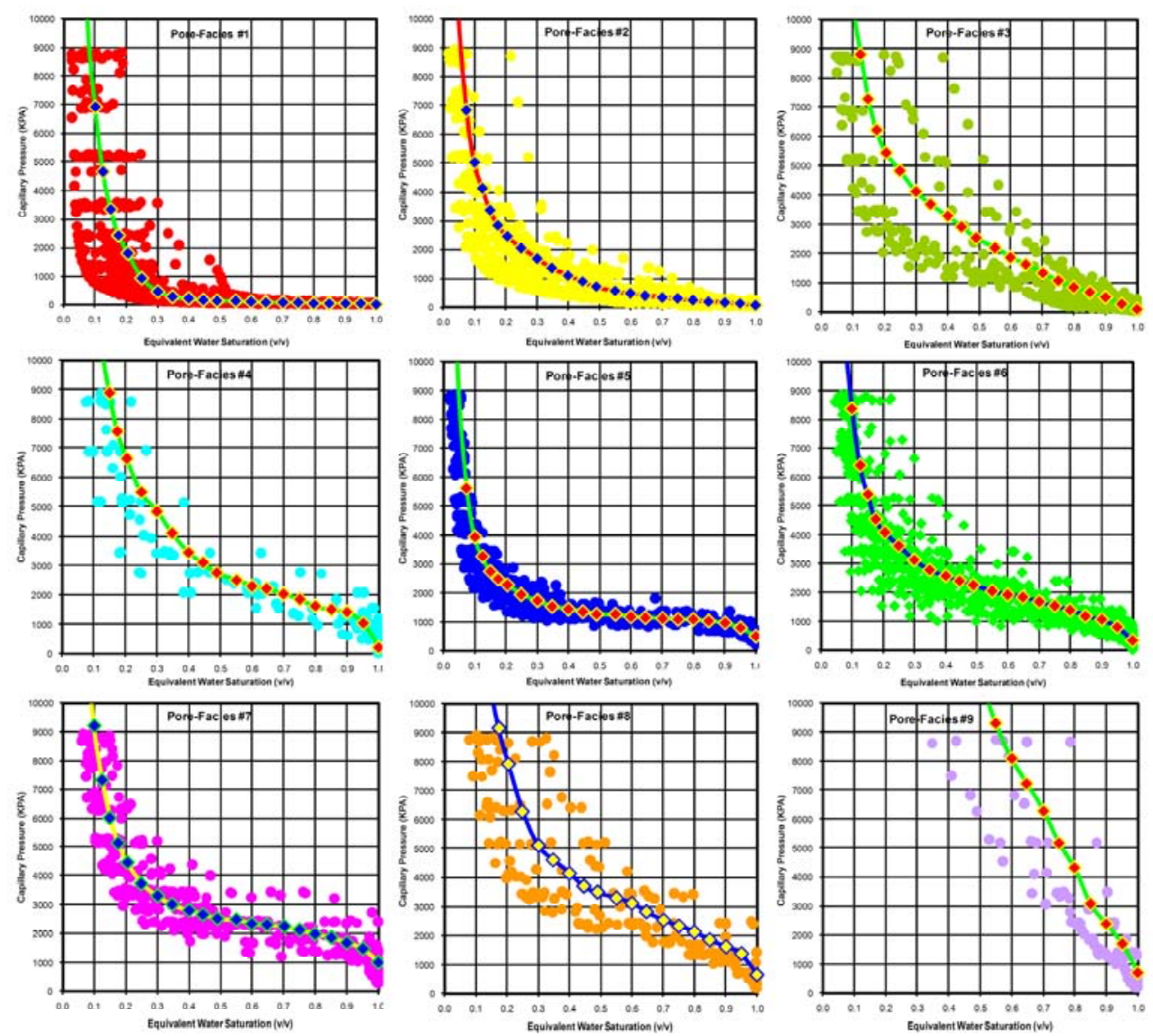

Figure 6 

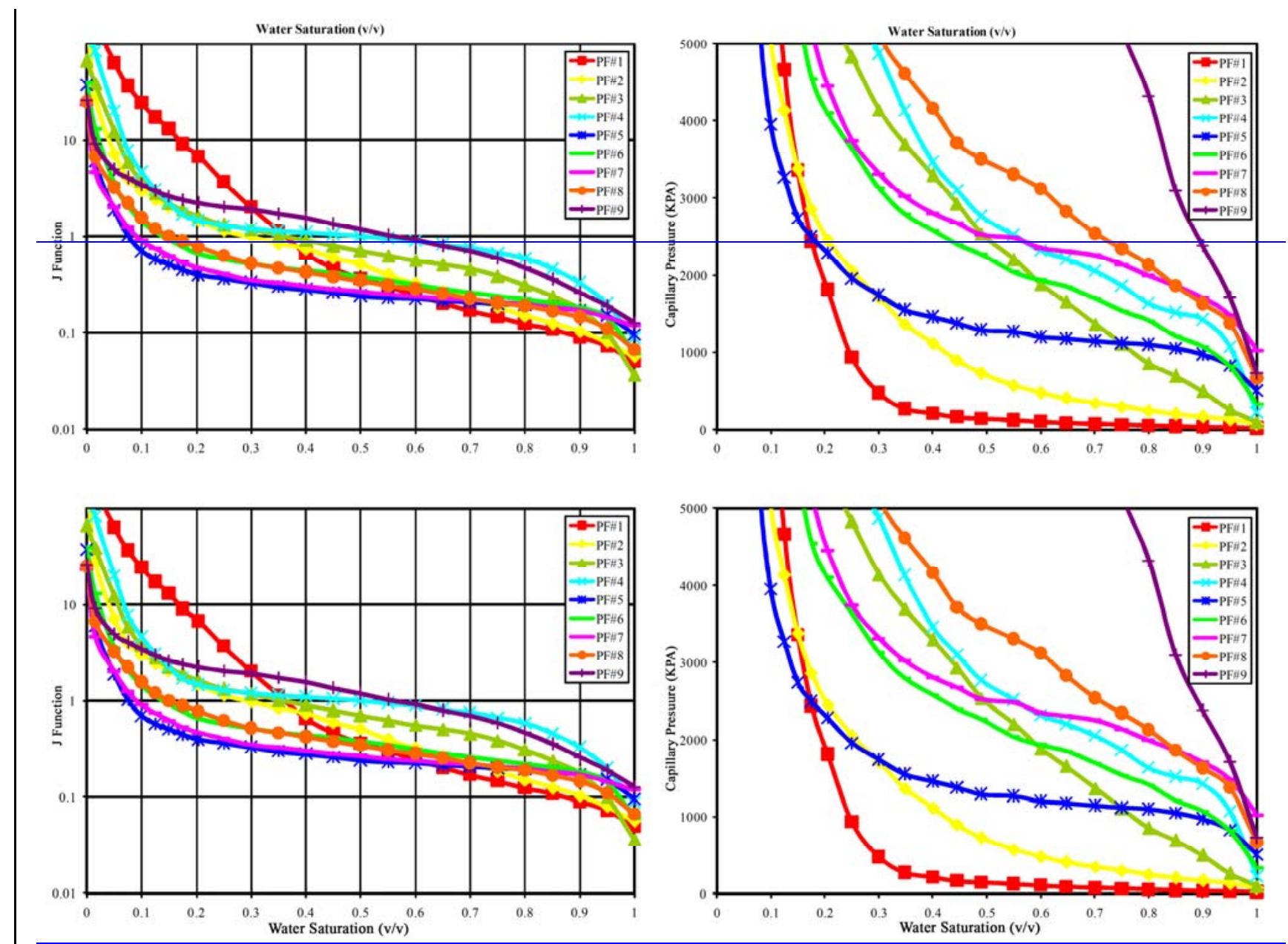

Figure 8 

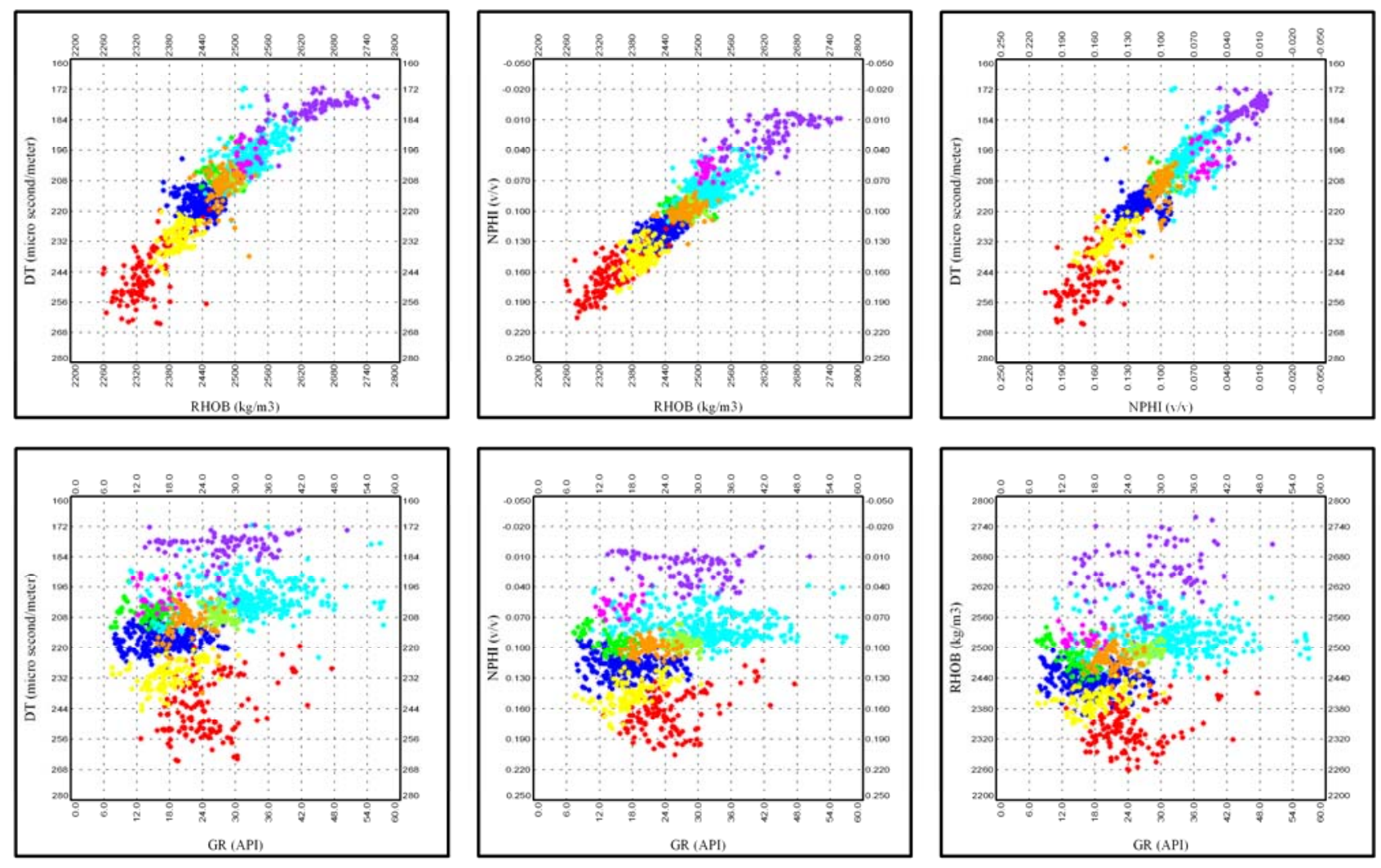

Figure 9 

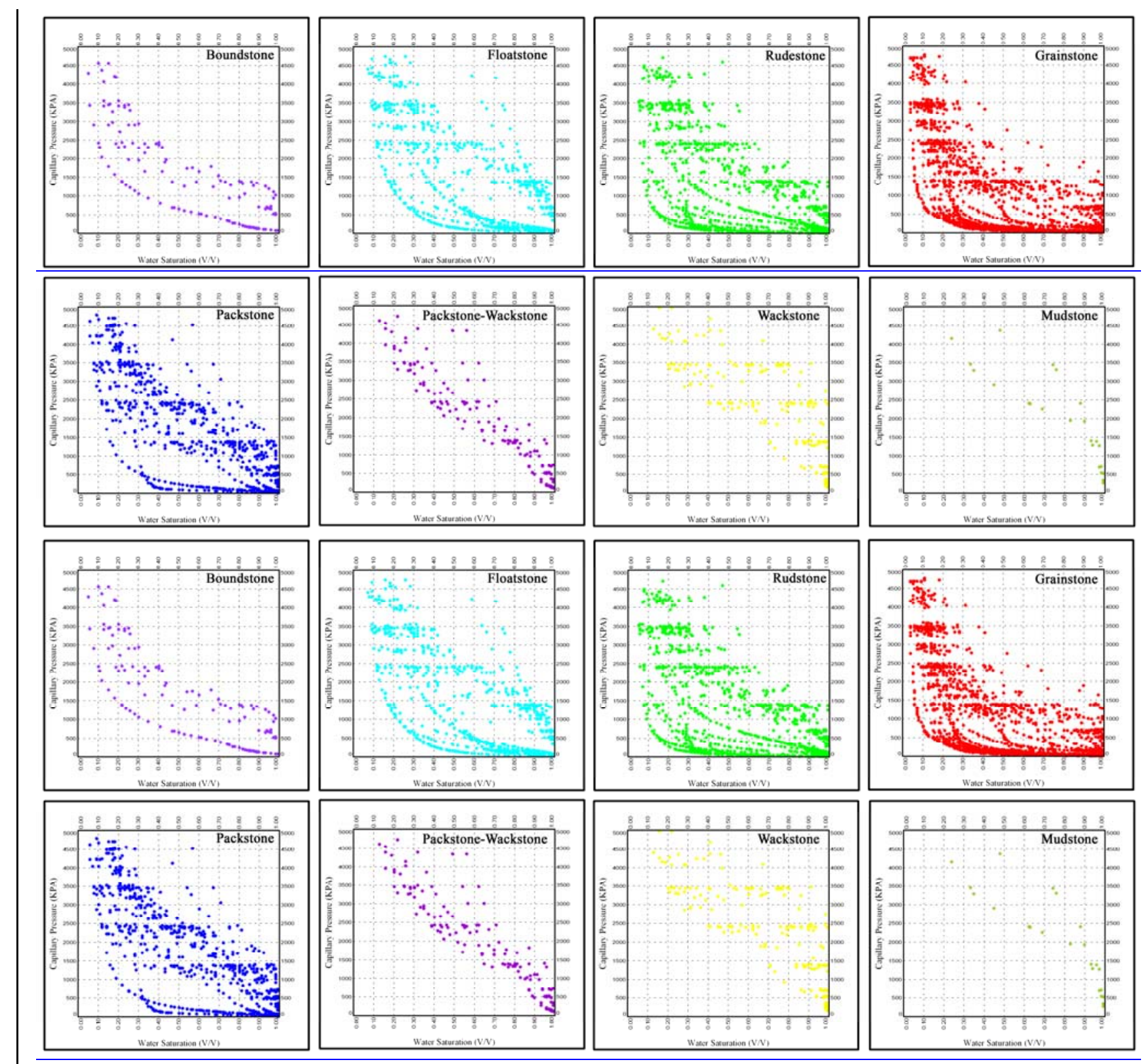
Figure 10 

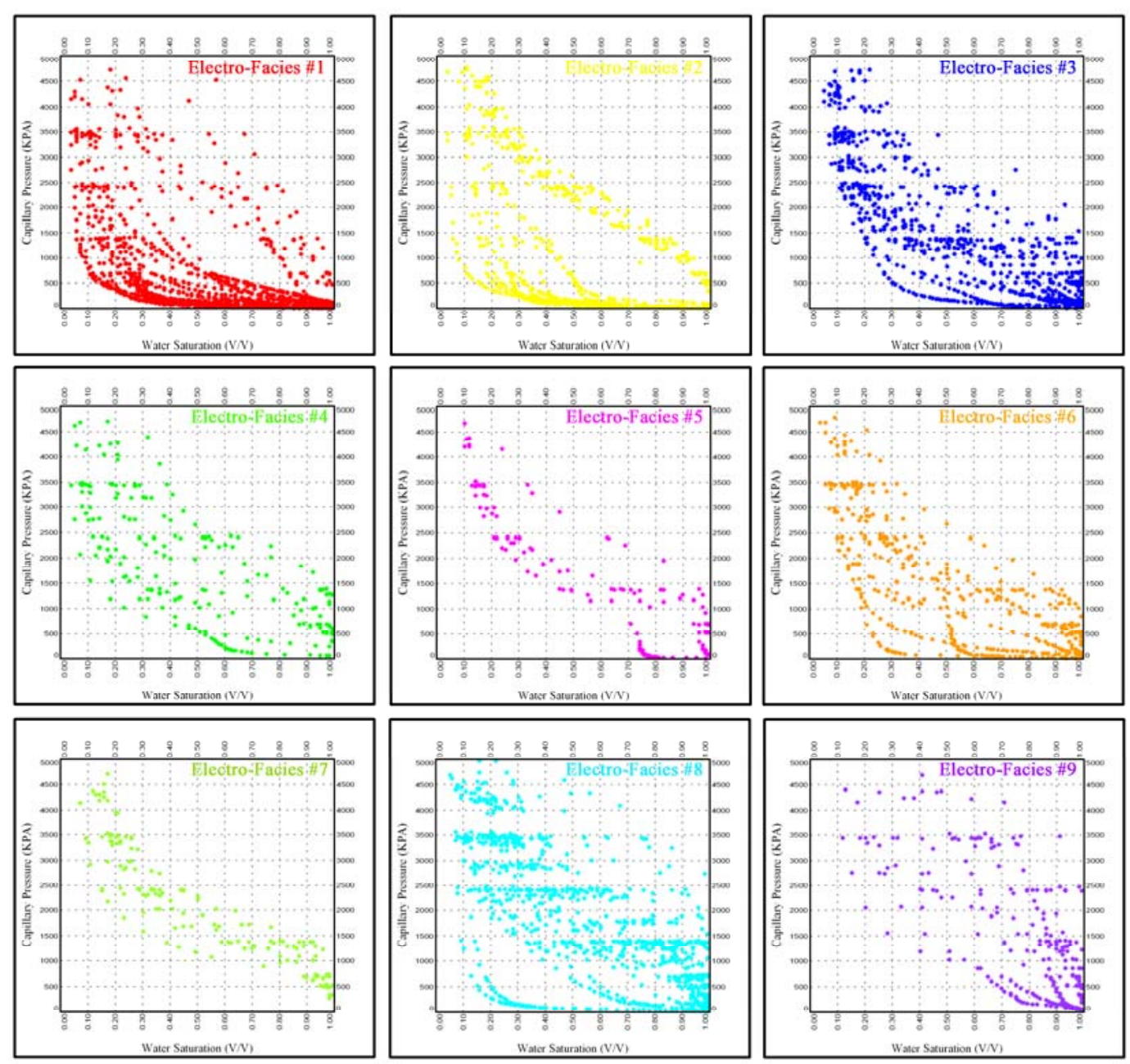

Figure 11 


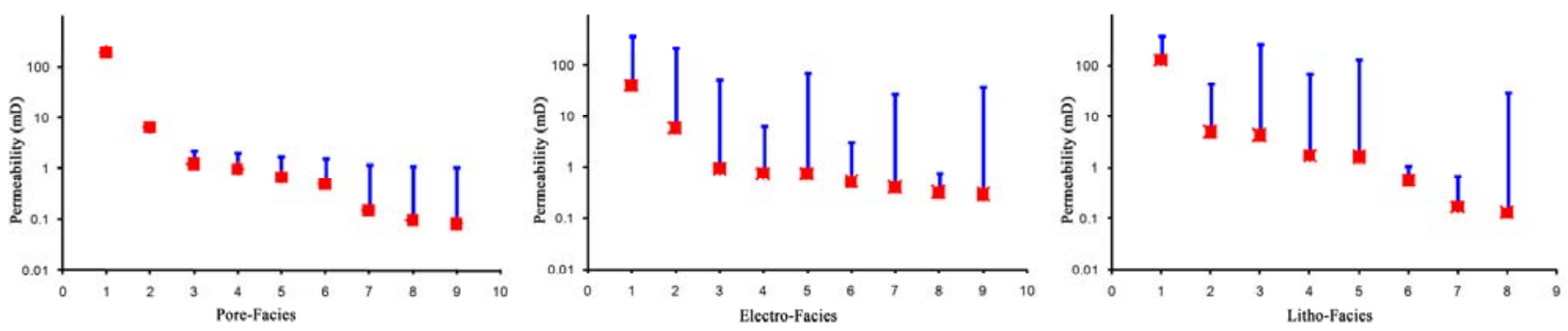

Figure 12 


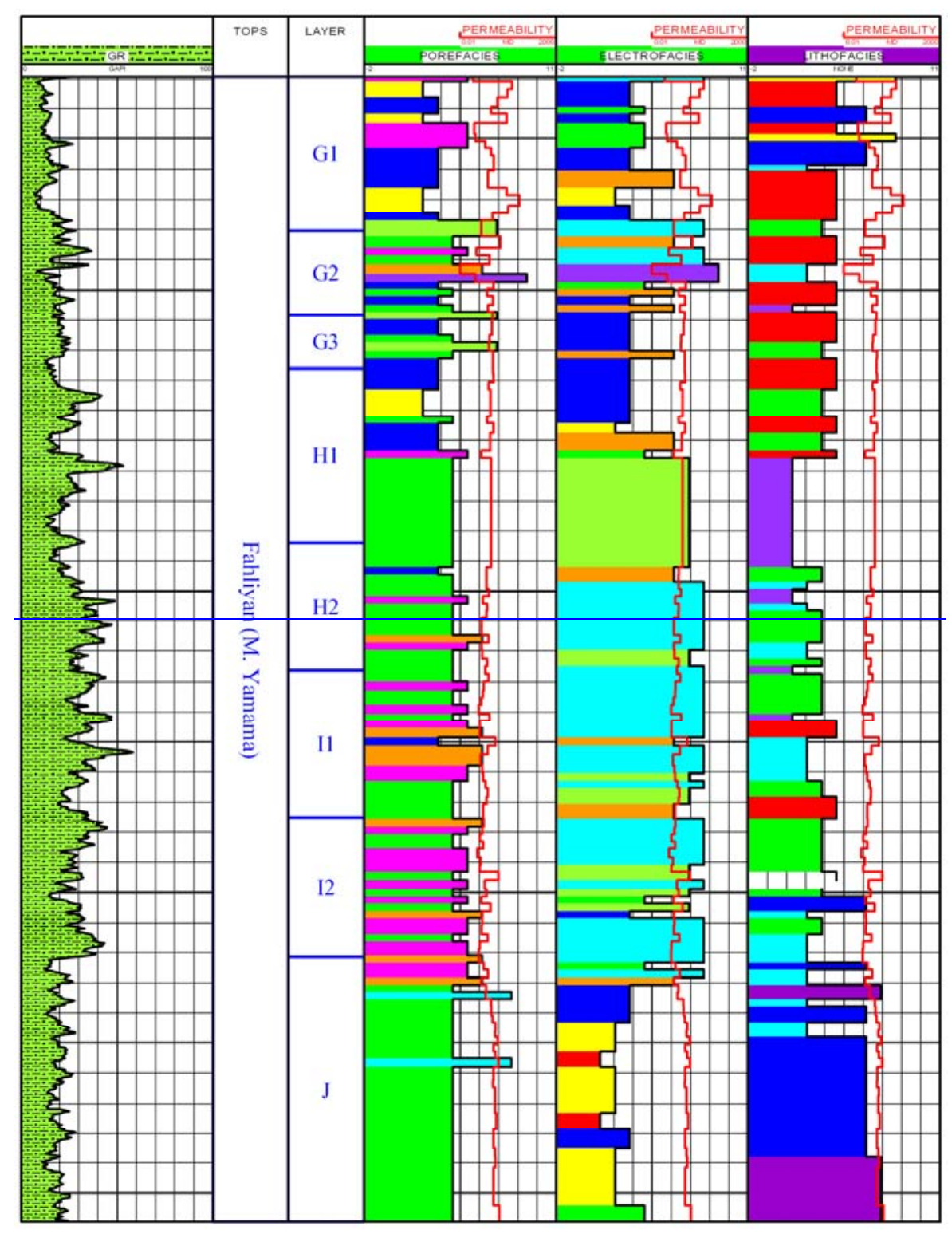




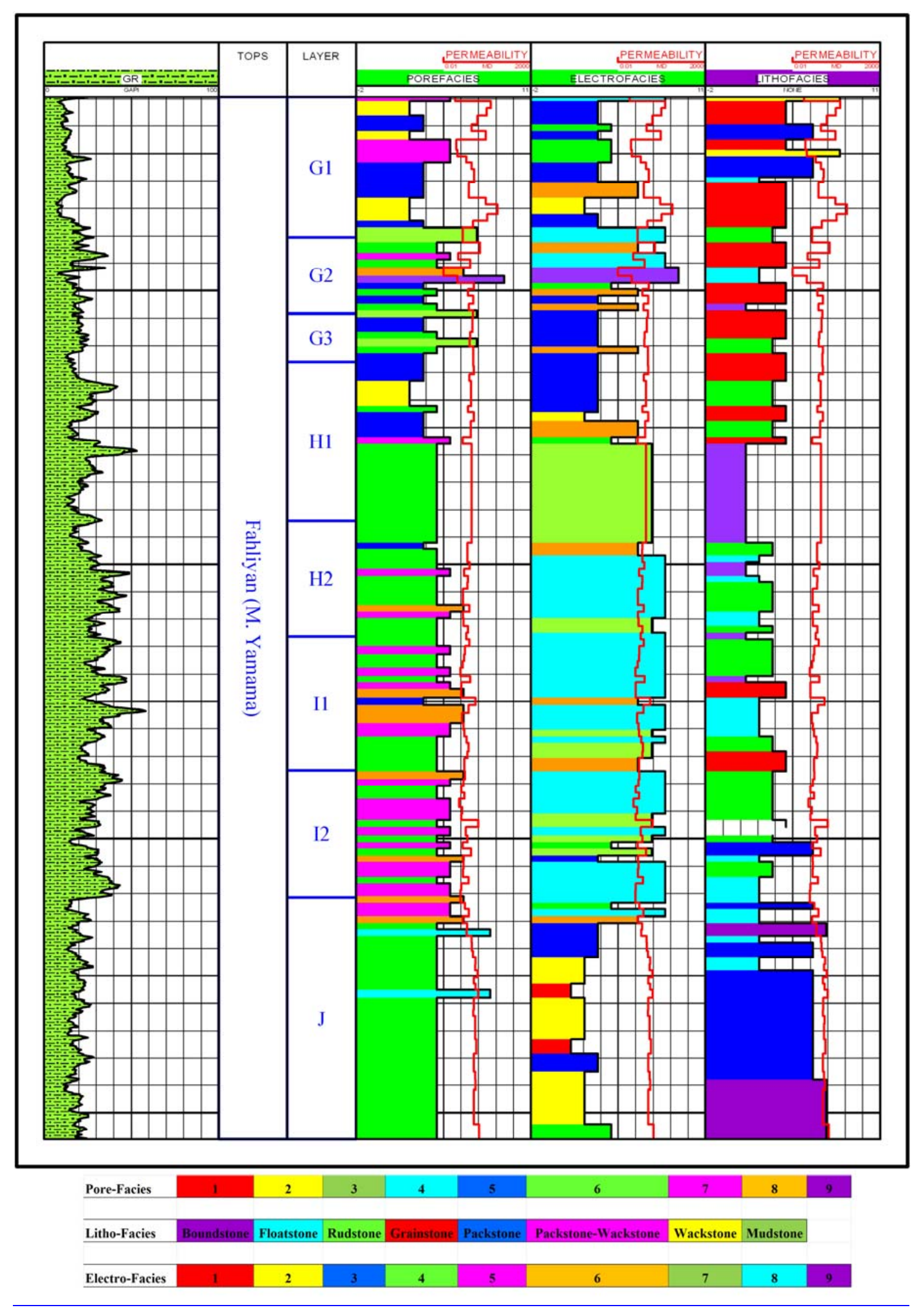

Figure 13 


\section{Figure's Captions}

Figure 1- The Dorood field is located in the northern part of the Persian Gulf, offshore Iran. Figure 2Stratigraphy of Fahliyan formation in Dorood field. This formation, composed completely of limestone, subdivided into 3 members and 13 reservoir layers.

Figure 3- Mercury Injection Capillary Pressure Curves from three wells. These curves span the whole range of water saturation vs. capillary pressure plot.

Figure 4- Water saturation vs. capillary pressure along with corresponding height above free water level and J function (left). Pore Throat Radius vs. Water saturation for calculation of Mean Hydraulic Radius (Middle). Pore Throat Radius vs. Normalized Pore Throat Size Distribution for determination of Pore Throat Size Distribution (Right).

Figure 5- cross-plot of various parameters extracted from MICP curves vs. permeability.

Figure 6- Cross-plot of water saturation vs. capillary pressure for 9 clusters identified based on clustering using MRGC. Each cluster shows a certain pattern of increase in capillary pressure with water saturation. MICP curves with different shapes are clearly well separated into meaningful clusters. The highlighted curve in each graph is the average representative curve for that cluster.

Figure 7-a- Pore-Facies \#1, thin section micrograph of intraclastic rudstone (left). Both porosity and permeability are good (13.6\% and $762 \mathrm{mD}$ respectively). Equivalent water saturation vs. capillary pressure (middle) and Pore throat radius vs. normalized pore throat size distribution function (right). MICP curve clearly shows bimodal pore throat size distribution, the first part of the curves (about $40 \%$ water saturation) corresponds to pore throat size larger than 10 microns with the dominant value of 50 microns and represented by a macro-ports in the photo micrograph. Because of the large pore throats, mercury inters into the sample without any difficulty and creates a flat MICP curve. The second part of the curve corresponds to pore throat size of 0.3 micron and is associated with micro-ports between particles. Corresponding parameters extracted from MICP curve are as follow: 
$\mathrm{RQI}=2.18, \mathrm{FZI}=14.93, \mathrm{MHR}=51.3$ micron, $\mathrm{PTS}=30$, Swanson=1.62, $\mathrm{RG}=1259, \mathrm{PGF}=-2.116$ and $\mathrm{R}_{\text {threshold }}=73.4$ micron. High reservoir quality of this facies is a consequence of extremely large pore throat sizes (more than $1 \mathrm{~mm})$. This pore-facies is usually seen in rudstones and some of grainstones.

Figure 7-b- Pore-Facies \#2, thin section micrograph of peloidal grainstone (left).Porosity and permeability of this sample is generally good $(17.7 \%$ and $17 \mathrm{mD}$ respectively. Equivalent water saturation vs. capillary pressure (middle) and pore throat radius vs. normalized pore throat size distribution function (right). MICP curve clearly shows bimodal pore throat size distribution, the first part of the curves (about $70 \%$ water saturation) corresponds to pore throat size larger than 1 micron with the dominant value of 5 microns and represented by a macro-ports in the photo micrograph. The second part of the curve corresponds to mean pore throat size of 0.7 micron and are associated with meso-ports between particles. Corresponding parameters extracted from MICP curve are as follow: $\mathrm{RQI}=0.28, \mathrm{FZI}=1.41, \mathrm{MHR}=2.5$ micron, $\mathrm{PTS}=2.22$, Swanson=0.22, $\mathrm{RG}=842, \mathrm{PGF}=-1.48$ and $\mathrm{R}_{\text {threshold }}=10.5$ micron. This pore-facies is mainly seen in grainstones and some packstones. Large pore throat sizes (because of dissolution) are responsible for high reservoir quality of this facies.

Figure 7-c- Pore-Facies \#3, thin section micrograph of ooid grainstone (left). Porosity and permeability of this sample is moderate (19.1\% and $6.1 \mathrm{mD}$ respectively). Equivalent water saturation vs. capillary pressure (middle) and pore throat radius vs. normalized pore throat size distribution function (right). MICP curve shows that pore throat radius ranges from 10 to 0.01 micron but the predominant pore throat size is 0.5 micron. Corresponding parameters extracted from MICP curve are as follow: $\mathrm{RQI}=0.16, \mathrm{FZI}=0.75, \mathrm{MHR}=1.28$ micron, $\mathrm{PTS}=0.69$, Swanson=0.04, $\mathrm{RG}=1038, \mathrm{PGF}=-1.65$ and $\mathrm{R}_{\text {threshold }}=6.67$ micron. This pore-facies is characterized with uniform pore throat size distribution and is mainly seen in grainstones and floatstones. Later pressure dissolution has reduced quality of this facies compared to facies\#2.

Figure 7-d- Pore-Facies \#4, thin section micrograph of dolomitic wackstone (left). Porosity can be considered poor due to the scarcity of molds. Permeability is also low due to the isolated nature of the molds. Measured permeability is higher than one might expect due to the relative abundance of open, natural fractures $(11.3 \%$ and $20 \mathrm{mD}$ respectively). Equivalent water saturation vs. capillary pressure (middle) and Pore throat radius vs. normalized pore throat size distribution function (right). Corresponding parameters extracted from MICP curve are as follow: $\mathrm{RQI}=0.39, \mathrm{FZI}=3.28, \mathrm{MHR}=0.23$ micron, $\mathrm{PTS}=0.31$, Swanson=0.02, $\mathrm{RG}=1660, \mathrm{PGF}=-1.24$ and $\mathrm{R}_{\text {threshold }}=0.82$ micron. This pore-facies is usually seen in packstones and wackstones. Many pores are filled with later cementations.

Figure 7-e- Pore-Facies \#5, thin section micrograph of peloidal grainstone (left). Porosity and permeability of this sample is $14 \%$ and $0.85 \mathrm{mD}$ respectively. Equivalent water saturation vs. capillary pressure (middle) and pore throat radius vs. normalized pore throat size distribution function (right). MICP curve shows that most of the pore throats are smaller than 1 micron which corresponds to the meso-ports of grain and cement dissolution. Corresponding parameters extracted from MICP curve are as follow: $\mathrm{RQI}=0.07, \mathrm{FZI}=0.45, \mathrm{MHR}=0.42$ micron, 
$\mathrm{PTS}=0.67$, Swanson=0.0031, $\mathrm{RG}=269, \mathrm{PGF}=-0.7$ and $\mathrm{R}_{\text {threshold }}=1.22$ micron. This pore-facies is abundant in highly cemented grainstones. Permeability of this facies is a consequence of later dissolution of less stable bioclasts.

Figure 7-f- Pore-Facies \#6, thin section micrograph of peloidal grainstone (left). Porosity and permeability of this sample is generally moderate (18.8\% and $2.65 \mathrm{mD}$ respectively), however extensive patches of calcite cementation occur in places, filling many interparticle pore spaces. Equivalent water saturation vs. capillary pressure (middle) and Pore throat radius vs. normalized pore throat size distribution function (right). MICP curve shows a uniform pore throat size distribution characterized by meso-ports in photo micrograph. The dominant pore throat radius is 0.4 micron, however this parameter ranges from 2 to 0.01 micron. Corresponding parameters extracted from MICP curve are as follow: $\mathrm{RQI}=0.11, \mathrm{FZI}=0.51, \mathrm{MHR}=0.42$ micron, $\mathrm{PTS}=0.52$, Swanson=0.04, $R G=921, P G F=-1.13$ and $R_{\text {threshold }}=1.83$ micron. This pore-facies is usually seen in grainstones. Reservoir quality of this facies has been degraded due to cementation of many of pore throats which created one way pass for fluid flow so in spite of having good porosity; its permeability is less than expectation.

Figure 7-g- Pore-Facies \#7, thin section micrograph of skeletal wackstone (left). Visual porosity is poor, although limited micro porosity may exist as secondary chalky porosity within the matrix $(9 \%$ and $0.14 \mathrm{mD}$ respectively). Equivalent water saturation vs. capillary pressure (middle) and Pore throat radius vs. normalized pore throat size distribution function (right). MICP curve clearly shows mono-modal pore throat size distribution with dominant value of 0.2 micron. Corresponding parameters extracted from MICP curve are as follow: $\mathrm{RQI}=0.04, \mathrm{FZI}=0.35, \mathrm{MHR}=0.24$ micron, $\mathrm{PTS}=0.26$, Swanson=0.0009, $\mathrm{RG}=630, \mathrm{PGF}=-0.74$ and $\mathrm{R}_{\text {threshold }}=0.52$ micron. This pore-facies is abundant in wackstones and packstone/wackstones and generally the pore throat sizes are smaller than 1 micron.

Figure 7-h- Pore-Facies \#8, thin section micrograph of lime wackstone (left). Porosity and permeability of this sample is $7 \%$ and $0.04 \mathrm{mD}$ respectively. Equivalent water saturation vs. capillary pressure (middle) and Pore throat radius vs. normalized pore throat size distribution function (right). Corresponding parameters extracted from MICP curve are as follow: $\mathrm{RQI}=0.02, \mathrm{FZI}=0.32, \mathrm{MHR}=0.44$ micron, $\mathrm{PTS}=0.17$, Swanson=0.0005, $R G=960, P G F=-0.91$ and $R_{\text {threshold }}=0.24$ micron. This pore-facies is abundant in wackstones.

Figure 7-i- Pore-Facies \#9, thin section micrograph of mudstone (left). Porosity and permeability of this sample is low ( $4 \%$ and $0.11 \mathrm{mD}$ respectively). Equivalent water saturation vs. capillary pressure (middle) and Pore throat radius vs. normalized pore throat size distribution function (right). Corresponding parameters extracted from MICP curve are as follow: $\mathrm{RQI}=0.05, \mathrm{FZI}=1.53, \mathrm{MHR}=0.82$ micron, $\mathrm{PTS}=0.07$, Swanson=0.0001, $\mathrm{RG}=2190, \mathrm{PGF}=-0.98$ and $\mathrm{R}_{\text {threshold }}=0.09$ micron. This pore facies is usually seen in mudstones. This facies has the lowest reservoir quality. 
Figure 8- Average PC curve (left) and J-Function (right) for different Pore-Facies. This J-Curve is a master curve that can be used to represent that reservoir and in the absence of other data can be used for other reservoirs of similar rock type.

Figure 9- Cross-plot of Density, Sonic, Gamma Ray and Neutron Porosity. Assuming the number of clusters to be 9 and using MRGC, clusters are well separated. Different colors in these cross-plots are representative of different Electro-Facies.

Figure 10- Capillary pressure vs. water saturation for different Litho-Facies. Samples range in texture from mudstone to Boundstone. MICP curves with different shape and signature have wrongly been categorized into a simple Litho-Facies.

Figure 11- Capillary pressure vs. water saturation for different Electro-Facies. MICP curves with different shape and signature have been categorized into a simple Electro-Facies.

Figure 12- Box plot of permeability within Pore-Facies (left), Electro-Facies (middle) and Litho-Facies (right). The squares indicate the mean and the straight lines show the standard deviation of permeability for each facies.

Figure 13- The sensitivity of Pore-Facies, Electro-Facies and Litho-Facies to permeability variations. The first track is GR, second and third tracks display formation and reservoir zonation respectively. Tracks 4-6 are PoreFacies, Electro-Facies and Litho-Facies respectively. The red blocked curves in these three tracks are measured permeability. Any real variation in permeability is reflected in Pore-Facies; however this is not the case for the Electro and Litho-Facies. 
Table 1- A total of 14 parameters selected for cluster analysis and their corresponding mean value for each cluster.

\begin{tabular}{llllllllllllllll}
\hline Cluster & Weight & SB/PC & PTS & Swanson & MHR & PGF & RG & R5 & R16 & R25 & R35 & R50 & R75 & R84 & R95 \\
\hline $\mathbf{1}$ & 25 & 0.03423 & 10.915 & 0.8035 & 17.5 & -1.670 & 453 & 47.258 & 24.286 & 16.178 & 13.081 & 7.908 & 1.506 & 0.551 & 0.089 \\
$\mathbf{2}$ & 22 & 0.02990 & 2.440 & 0.1853 & 3.62 & -1.185 & 390 & 9.467 & 5.861 & 3.549 & 2.312 & 1.131 & 0.492 & 0.325 & 0.108 \\
$\mathbf{3}$ & 37 & 0.00144 & 0.574 & 0.0452 & 0.37 & -0.760 & 355 & 1.049 & 0.823 & 0.737 & 0.684 & 0.596 & 0.394 & 0.302 & 0.114 \\
$\mathbf{4}$ & 73 & 0.00204 & 0.407 & 0.0280 & 0.35 & -0.897 & 652 & 1.012 & 0.658 & 0.544 & 0.469 & 0.388 & 0.247 & 0.175 & 0.058 \\
$\mathbf{5}$ & 33 & 0.00065 & 0.293 & 0.0179 & 0.2 & -0.749 & 672 & 0.573 & 0.432 & 0.389 & 0.353 & 0.309 & 0.203 & 0.143 & 0.051 \\
$\mathbf{6}$ & 13 & 0.00073 & 0.262 & 0.0133 & 0.28 & -0.941 & 1046 & 0.736 & 0.452 & 0.371 & 0.306 & 0.237 & 0.145 & 0.096 & 0.031 \\
$\mathbf{7}$ & 14 & 0.00684 & 0.713 & 0.0375 & 1.93 & -1.396 & 1021 & 4.350 & 1.531 & 0.967 & 0.640 & 0.442 & 0.245 & 0.166 & 0.050 \\
$\mathbf{8}$ & 8 & 0.00107 & 0.298 & 0.0181 & 0.24 & -1.205 & 1652 & 0.738 & 0.475 & 0.420 & 0.363 & 0.299 & 0.183 & 0.121 & 0.028 \\
$\mathbf{9}$ & 6 & 0.00036 & 0.138 & 0.0029 & 0.32 & -0.858 & 1876 & 0.617 & 0.302 & 0.195 & 0.128 & 0.082 & 0.043 & 0.032 & 0.020 \\
\hline
\end{tabular}


Table 2- Petrophysical properties and main parameters extracted from MICP curves for each pore-facies.

\begin{tabular}{lllllllllllllll}
\hline Pore-Facies & Weight & K & PHI & RQI & FZI & m & SB/PC & PTS & Swanson & MHR & PGF & RG & Re & Rt \\
\hline $\mathbf{1}$ & 25 & 193.323 & 0.198 & 1.050 & 4.580 & 2.148 & 0.03423 & 10.915 & 0.8035 & 17.500 & -1.670 & 453 & 101.168 & 101.168 \\
$\mathbf{2}$ & 22 & 6.533 & 0.182 & 0.200 & 0.876 & 2.033 & 0.02990 & 2.440 & 0.1853 & 3.620 & -1.185 & 390 & 17.891 & 13.089 \\
$\mathbf{3}$ & 14 & 1.229 & 0.129 & 0.101 & 0.726 & 1.830 & 0.00684 & 0.713 & 0.0375 & 1.930 & -1.396 & 1021 & 10.798 & 4.397 \\
$\mathbf{4}$ & 8 & 0.965 & 0.128 & 0.113 & 0.844 & - & 0.00107 & 0.298 & 0.0181 & 0.240 & -1.205 & 1652 & 1.216 & 0.699 \\
$\mathbf{5}$ & 37 & 0.673 & 0.148 & 0.064 & 0.372 & 1.883 & 0.00144 & 0.574 & 0.0452 & 0.370 & -0.760 & 355 & 2.018 & 1.022 \\
$\mathbf{6}$ & 73 & 0.492 & 0.141 & 0.058 & 0.368 & 1.763 & 0.00204 & 0.407 & 0.0280 & 0.350 & -0.897 & 652 & 2.096 & 0.957 \\
$\mathbf{7}$ & 33 & 0.155 & 0.113 & 0.036 & 0.305 & 1.766 & 0.00065 & 0.293 & 0.0179 & 0.200 & -0.749 & 672 & 1.088 & 0.523 \\
$\mathbf{8}$ & 13 & 0.095 & 0.102 & 0.031 & 0.279 & - & 0.00073 & 0.262 & 0.0133 & 0.280 & -0.941 & 1046 & 1.835 & 0.791 \\
$\mathbf{9}$ & 6 & 0.081 & 0.055 & 0.042 & 0.958 & 1.770 & 0.00036 & 0.138 & 0.0029 & 0.320 & -0.858 & 1876 & 1.842 & 0.540 \\
\hline
\end{tabular}

